\title{
EL SAXOFÓN EN LA ÓPERA DE LUIS DE PABLO: LA SEÑORITA CRISTINA
}

\section{THE SAXOPHONE IN THE OPERA IN THE OPERA OF LUIS DE PABLO: LA SEÑORITA CRISTINA}

\author{
Francisco Martínez García \\ Universidad Autónoma de Madrid
}

\section{Resumen}

A sus 82 años no vamos a citar la importancia e influencia de Luis de Pablo en la historia musical de España en los últimos cincuenta años, pero no fue esto lo que me llamó la atención para realizar una tesis doctoral sobre su música ${ }^{1}$, sino la gran producción de obras con saxofón dentro de su catálogo: veinticinco obras al momento de hoy ${ }^{2}$. Es un número muy alto comparándolo con lo que los compositores europeos de primera línea han llevado a cabo durante el siglo XX y primera década del XXI. De toda esta gran producción, destacan sin duda sus óperas, ya que en tres de sus cinco obras de este apartado, el saxofón está presente y además con funciones de personaje dramático. A continuación vamos a efectuar un análisis de la ópera La señorita Cristina y del empleo del saxofón en la misma, con unas aportaciones musicales que once años después de su estreno son sin duda novedosas y muy interesantes.
\end{abstract}

\section{Palabras clave}

Análisis de ópera, Luis de Pablo, Ópera, Saxofón en la ópera, Mircea Eliade, Vampirismo en la música, Saxofón total, Ópera contemporánea.

\begin{abstract}
At 82 years we will not mention the importance and influence of Luis de Pablo in the musical history of Spain in the last fifty years, but it was not what caught my attention for a $\mathrm{PhD}$ thesis on his music, but the the large number of works including saxophone in his catalog: 25 works upon today. It is a very high number compared to what Europeans frontline composers have produced during the twentieth century and the first decade of the 21 st. From all this great production, surely excel his operas, as three of his five works dedicated to this genre, the saxophone is present and also with dramatic character roles. Then we will make an analysis of the opera La señorita Cristina, and the employment of the saxophone there, with musical contributions that eleven years after its release are certainly innovative and interesting.
\end{abstract}

\section{Key Words}

Opera Analysis, Luis de Pablo, Opera, Operatic saxophone, Mircea Eliade, Vampirism in music, Total saxophone, Contemporary opera.
1 Recientemente he realizado una tesis doctoral a propósito de la música para saxofón del compositor Luis de Pablo, bajo la dirección de Enrique Muñoz.

2 Su catálogo cuenta a día de hoy con unas 210 obras. El autor considera fuera de catálogo sus 57 películas y 6 obras de teatro. 


\section{Introducción}

Luis de Pablo siempre ha tenido una especial predilección por la música teatral. Antes de la ópera había tenido aproximaciones y experiencias en el campo de la música y la palabra, con obras teatrales - o con acción- como Protocolo, Por diversos motivos, Masque, Berceuse, Sólo un paso y Very Gentle, todas ellas del periodo entre 1968 y 1974. Más amplia es la relación de composiciones con voz solista o con coro y una agrupación instrumental ${ }^{3}$, entre las que cabría destacar Viatges i Flors (1981-84), Antigua Fe (1990), De la América pretérita (1991), Sonidos de la guerra (1980) o, Tarde de poetas (1985-86), hasta un número de 33 obras. Pero las primeras, o sea la música con acción, son lo que hoy podríamos decir, un prefacio de su decisión de introducirse en el mundo de la ópera.

Una de las razones que le llevó a componer ópera fue que siempre había tenido un gran deseo de promover la lengua española en el campo de la música. En el texto siguiente, muestra su interés por la lengua castellana y por la búsqueda de un texto para su primera ópera, Kiu:

[...] todo lo que yo he hecho en diálogo con la palabra ha sido fundamentalmente profundizar todo lo que yo he sido capaz en las posibilidades musicales de la lengua castellana. Eso yo tengo que subrayarlo con lápiz rojo. Yo pienso que la lengua castellana en tiempos modernos ha estado infrautilizada, salvo en el folklore. La música popular ha encontrado soluciones admirables para el pueblo, pero en la música llamada culta desde hace 200 años aproximadamente parece que los compositores no se han interesado en servir a la lengua española con la misma profundidad que otros compositores se han servido de la lengua de sus países ${ }^{4}$.

Sobre la música vocal de Luis de Pablo, José Luis García del Busto escribe en una de sus últimas publicaciones:

[...] En la música vocal de Luis de Pablo no sólo se observan las lógicas correspondencias expresivas que se derivan del contenido textual, sino algo más hondo en pura música como es el hecho de que el compositor busca abiertamente una vocalitá - "la" vocalitápropia de la lengua sobre la que trabaja. Por otra parte, si bien a De Pablo le repele cualquier planteamiento musical descriptivista, es cierto que gusta en ocasiones de componer al hilo de situaciones literarias, poéticas y hasta escénicas que imponen una determinada ordenación y fisonomía al discurso musical, sea o no perceptible tal cosa para el oyente ${ }^{5}[\ldots]$.

La primera ópera fue Kiu, estrenada en 1983 en el teatro de la Zarzuela, a ésta le siguieron El viajero indiscreto, La madre invita a comer y La señorita Cristina. Estas tres últimas emplean el saxofón. A estas óperas les continuó la titulada Un parque, del año 2005, y que no incluye saxofón.

La última acción del compositor al respecto de sus óperas ha sido la revisión completa de El viajero indiscreto. Esta revisión afecta sobre todo a su duración que se ha visto reducida aproximadamente en una cuarta parte. El autor terminó esta revisión en el año 2010 y todavía no se ha estrenado.

En este artículo vamos a efectuar un análisis completo de La Señorita Cristina y del empleo del saxo en la misma, ya que el compositor utiliza el saxofón de una manera relevante, teniendo incluso un rol dramático, como veremos a continuación.

\section{La señorita Cristina.}

LA SEÑORITA CRISTINA (1997/99) ópera en tres actos sobre libreto de Luis de Pablo, realizado con una adaptación de "La señorita Cristina" de Mircea Eliade. $\left(120^{\prime}\right)$

. - Partitura, reproducción del manuscrito del autor. (284 p.); $57 \mathrm{~cm}$. (3.3.3.3. 1 Sax [sp.alt.bar].- 4.3.3.1. - Pf. - Ar. - Cel. - 3 Tp. [1 es.] - 5 Perc.[Manico d'ombrello, 3 Tot., 3 Cv., Xyl., Tamb. s.c., Tal., Trg., 2 Flex., Gc., Glock., Cp., Steel Drum. Ps., N., Quijada, 2 Tt., Mr., Fl. De Jazz, Vibr., Tbl., Tamb. con o sin bordon, Bg., Son., Plancha de metal] - 2 Ocarina - A.: 12.12.10.8.6.).

. - Milán: Ed. Suvini Zerboni, 1999.

- - Estreno en febrero de 2001 en el Teatro Real, Sinfónica de Madrid. Dir. José Ramón Encinar. (Encargo del Teatro Real de Madrid con motivo de su 150 aniversario)

. - Dedicada a Mario Bortolotto.

3 Se incluyen obras con acompañamiento de orquesta o conjunto instrumental.

4 PABLO, Luis de: Entrevista VI, Anexo VI, en: MARTINEZ GARCIA, 2011.

5 GARCÍA DEL BUSTO, 2007: 107. 


\section{Contexto general de la obra}

El 10.02.2001 se estrena en el Teatro Real de Madrid, por la Orquesta Sinfónica de Madrid bajo la dirección de José Ramón Encinar, La Señorita Cristina, la cuarta ópera de Luis de Pablo, con libreto propio sobre la novela homónima de Mircea Eliade. Ópera en tres actos y diez escenas, la dirección escénica estuvo a cargo de Francisco Nieva. El encargo fue con motivo del 150 aniversario del Teatro Real de Madrid y de todas las óperas de Luis de Pablo ésta es la de mayor montaje escénico y una de las de mayor duración ${ }^{6}$.

La partitura especifica que un solo intérprete debe tocar los saxofones soprano y barítono, pero analizando la partitura hemos observado tres intervenciones del saxofón alto. La mayor parte de la obra está escrita para el saxofón barítono, ya que sólo hay, aparte de las mencionadas apariciones del saxofón alto, una única en varios solos, del soprano en la escena segunda. Preguntado al autor sobre el papel del saxo, nos respondió lo siguiente:
El saxofón de alguna forma es el instrumento que encarna a Cristina en la mayor parte de las veces. Hay un cierto material temático que acompaña a las alusiones y a la presencia de Cristina y eso está fundamentalmente dado siempre por el saxo. Por otra parte, el saxo es el que termina la obra, porque lo último que se dice en la obra es la exclamación de Egor, el protagonista, que dice: ¡Ah, Cristina! No me atrevo a decir que el saxo conduzca la acción, porque sería excesivo, pero aparece la mayoría de las veces en las que se alude a Cristina ${ }^{7}$.

\section{Análisis de la obra}

La obra está dividida en tres actos. Cada uno de ellos tiene una introducción y, además, cuatro escenas el primero, tres el segundo y tres el tercero.

La introducción de la ópera, de 36 compases de duración, corre a cargo de la cuerda de la orquesta: La obra comienza por un solo de siete compases de los violonchelos, (Fig. 1) nota $\mathrm{n}^{\circ} 3$ a un tempo de $\bullet=132$.

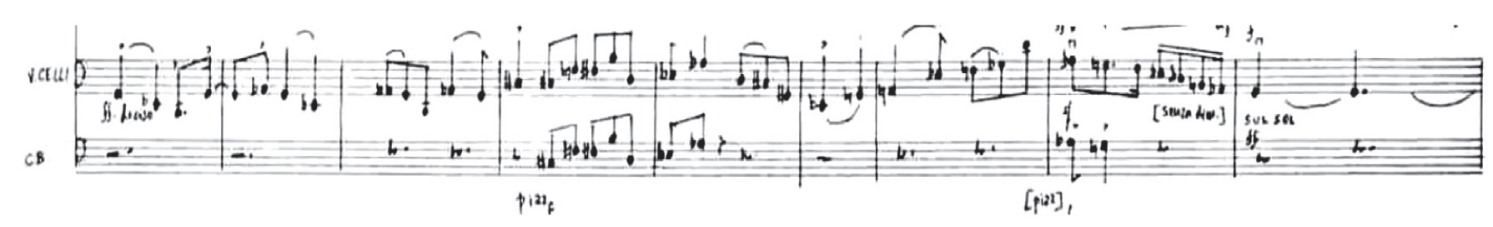

Fig. 1. Solo de violonchelos al inicio de la obra

Después de un acorde en el compás 8 , continúa el discurso de esta introducción con una melodía al unísono por parte de toda la cuerda de la orquesta (Fig. 2), con la cual el compositor quiere introducir una nota de suspense sobre el devenir del argumento.

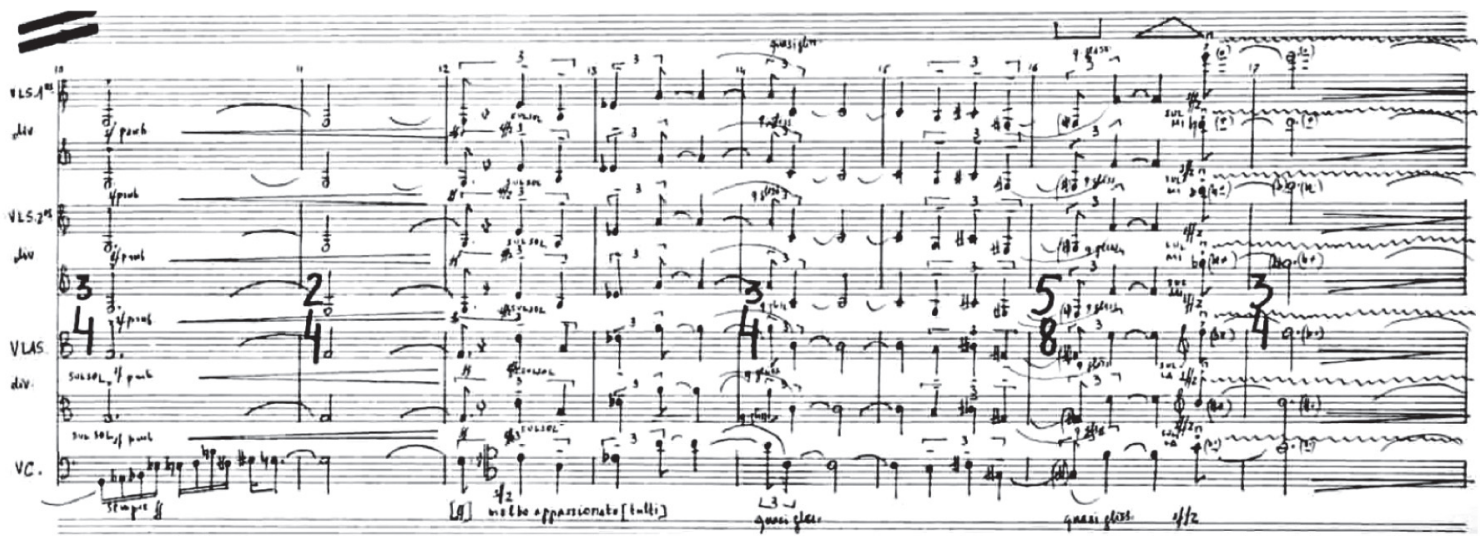

Fig. 2. Melodía al unísono de la introducción por la cuerda

6 El viajero indiscreto es la ópera de mayor duración, con una última revisión que está por estrenar.
7 PABLO, Luis de: Entrevista VI, Anexo VI, en: MARTINEZ GARCIA, 2011. 
Al respecto de esta introducción el compositor nos comenta:

Esa gran melodía de la cuerda al unísono es como un preludio para introducir algo que no se sabe muy bien qué va a ser, es claramente un recitativo, eso podría haberlo hecho una voz evidentemente cambiando de tesitura haciéndola vocal, no instrumental como es, como una especie de: Y ahora se va a abrir el telón y veremos a ver lo que pasa $[\ldots]^{8}$.
No es una obertura al uso operístico: no olvidemos el propósito constante del autor de reinventar la forma musical. En el caso de las óperas, el autor nos comenta que la música está al servicio de la acción dramática:

Entonces hay, como debe haberlo en cada ópera, una cierta correspondencia entre la acción dramática y la música. Esto no quiere decir que la música sea una servidora de la acción dramática, sino que lo que es... es una potenciadora de la acción dramática en un plano mucho más fuerte que lo que pueda dar la palabra sola ${ }^{9}$.

\section{Esquema formal, $\mathbf{1}^{\circ}$ acto.}

\begin{tabular}{|c|c|c|c|c|}
\hline Introducción & ${\text { Escena } 1^{\circ}}^{\circ}$ & Escena $2^{\circ}$ & Escena $3^{\circ}$ & Escena $4^{\circ}$ \\
\hline $\begin{array}{l}\text { Introducción muy } \\
\text { corta y a cargo de la } \\
\text { cuerda de la orquesta. } \\
\text { Comienza con un solo } \\
\text { de violonchelos y } \\
\text { unísonos en la cuerda. }\end{array}$ & $\begin{array}{l}\text { Esta escena } \\
\text { aparecen } 6 \text { de } \\
\text { las voces. Toda } \\
\text { la escena esta } \\
\text { orquestada solo } \\
\text { con la cuerda. } \\
\text { Intermedio de } 20 \\
\text { compases. }\end{array}$ & $\begin{array}{l}\text { Diálogo entre Egor y } \\
\text { Nazarie, Participación } \\
\text { de toda la orquesta. } \\
\text { Aparece el saxo soprano } \\
\text { en primer lugar y el } \\
\text { barítono después. } \\
\text { Intermedio de } 31 \\
\text { compases. }\end{array}$ & $\begin{array}{l}\text { Escena en el desayuno. } \\
\text { Dialogo entre Nazarie } \\
\text { y Simina. Orquestación } \\
\text { buscando el diálogo entre } \\
\text { grupos orquestales y la } \\
\text { alternancia tímbrica. } \\
\text { Abundancia de unísonos. } \\
\text { Intermedio de } 22 \text { compases }\end{array}$ & $\begin{array}{l}\text { Diálogo entre } \\
\text { Egor y Nazarie. La } \\
\text { instrumentación } \\
\text { es más densa con } \\
\text { dinámicas mayores } \\
\text { que buscan una } \\
\text { descarga de la tensión } \\
\text { en el acorde final. }\end{array}$ \\
\hline 36 & 325 & 215 & 225 & 253 \\
\hline 1 (compases) & & & & 1018 \\
\hline
\end{tabular}

La primera escena transcurre en el comedor de una vieja casa de campo en los años 30, no lejos de un río. La casa ha debido ser lujosa hacia 1900. Principios de otoño del siglo $\mathrm{XX}^{10}$.

Es una descripción del argumento y del entorno social. La primera intervención de las voces es a cargo de Sanda
(Fig. 3). En esta escena aparecen seis de las ocho voces: Sanda, Egor, Moscu, Nazarie, Simina y Sirvienta. Los metrónomos son muy variables en función de las necesidades de las voces y de la acción dramática. Hay diferentes velocidades a $\downarrow=132, \downarrow=60, \downarrow=84, \downarrow=112, \downarrow=100, \mathrm{y} \cdot \bullet=58$.

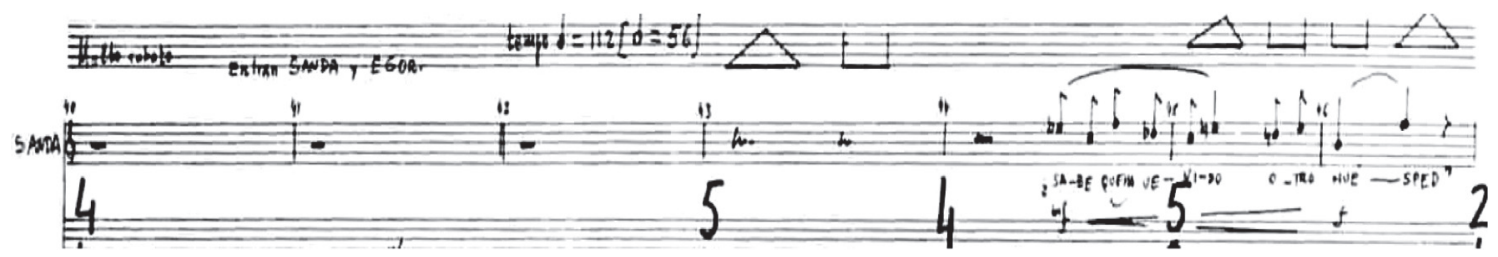

Fig. 3. Primera intervención de las voces a cargo de Sanda

8 PABLO, Luis de: Entrevista VI, Anexo VI, en: MARTINEZ GARCIA, 2011.

9 PABLO, Luis de: Entrevista VI, Anexo VI, en: MARTINEZ GARCIA, 2011.

10 PABLO COSTALES, 2001: 24. 
Toda la primera escena está orquestada con instrumentos de la sección de cuerda. El compositor, según nos comenta, ha dispuesto un esquema previo de instrumentación por escenas:

Una parte importante de la obra es el reparto de instrumentos en cada escena. El arranque de la obra no tiene más que cuerda y, sin embargo, se alude a Cristina, quien todavía no se sabe quién es, pero el saxo no está presente porque en el reparto de ese número esta solo la cuerda $^{11}[\ldots]$.

Las voces cantan alternativamente haciendo una presentación de los personajes, tanto de los presentes como de los ausentes. No hay momentos de tensión ni en el argumento ni en la música, no hay dinámicas extremas. Al final de la escena, 20 compases de intermedio orquestal permiten la preparación de la siguiente escena.

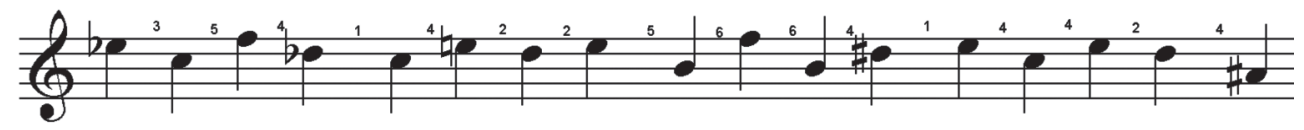

Fig. 4. Estudio de las sucesiones interválicas de Sanda en su primera intervención

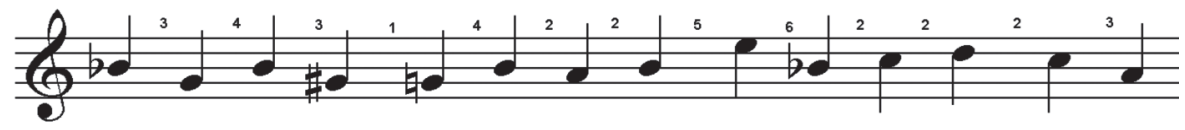

Fig. 5. Estudio de las sucesiones interválicas de Egor en su primera intervención

En el tratamiento de las voces abundan los intervalos de tercera mayor y menor, cuarta, algunas quintas y segundas (Figs. 4-5). La ordenación vertical se mueve en el principio con bastantes unísonos, o en acordes de agregados como en la introducción, que presenta en el compás 53 un acorde con la citada técnica propia de Luis de Pablo (Fig. 6), habitualmente de tercera mayor y quinta justa y terceras menores. Estos acordes sumados en esta interválica carecen de función tonal alguna. De ahí lo de la denominación de agregados.

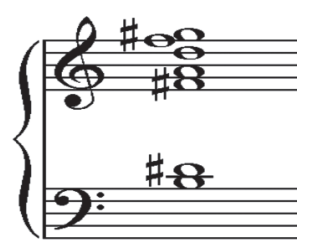

Fig. 6. Acorde del compás 53

11 PABLO, Luis de: Entrevista VI, Anexo VI, en: MARTINEZ GARCIA, 2011. 
La segunda escena transcurre en la habitación-dormitorio de Egor:

Es una habitación de invitados de una casa de campo con las mismas características que el comedor de la escena I. Tiene una gran ventana que da al jardín. La puerta de acceso a la habitación da a un pasillo invisible. Es de noche ${ }^{12}$.
En esta escena intervienen únicamente las voces de Egor y Nazarie. Las intervenciones de cada voz tienen siempre un inicio recurrente por los mismos intervalos. En el caso de Nazarie, siempre empieza sus intervenciones con una nota repetida para las dos primeras sílabas (Fig. 7).

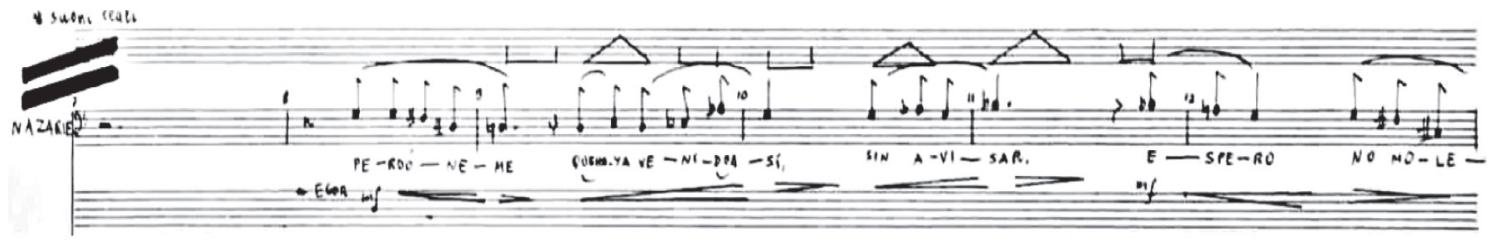

Fig. 7. $1^{\circ}$ intervención de Nazarie en la segunda escena

En el caso de Egor, siempre empieza sus intervenciones con una segunda menor descendente y una tercera menor descendente (Fig. 8).

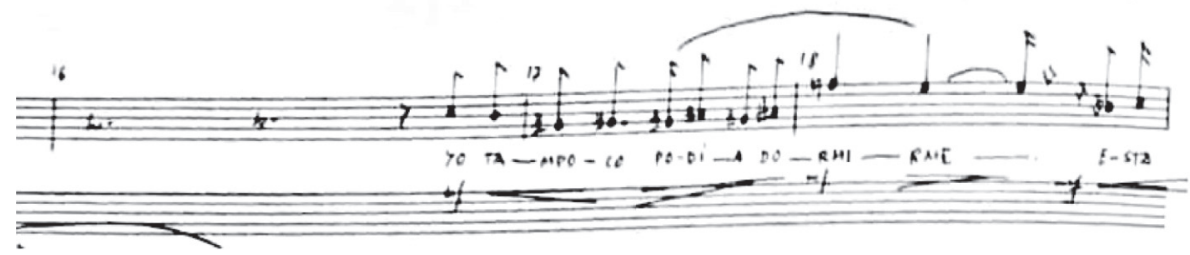

Fig. 8. $1^{\circ}$ intervención de Egor en la segunda escena

En esta escena ya aparece toda la orquesta y el saxo también se presenta por primera vez en su función dramática:

En esta escena, el saxo está presente y es un instrumento que representa a un personaje en lo que el instrumento es: su sonido su color y su material temático, unos ciertos intervalos que son recurrentes, etc. El saxo como materia tímbrica es muy reconocible y eso sí que se puede poner en valor, el saxo es muy protagonista del personaje en todas su manifestaciones ${ }^{13}[\ldots]$

La primera aparición es del saxo soprano en el compás 117 (Fig. 9). En el compás 142 a 144 el saxo soprano efectúa un acompañamiento a la voz de Nazarie (Fig. 10).

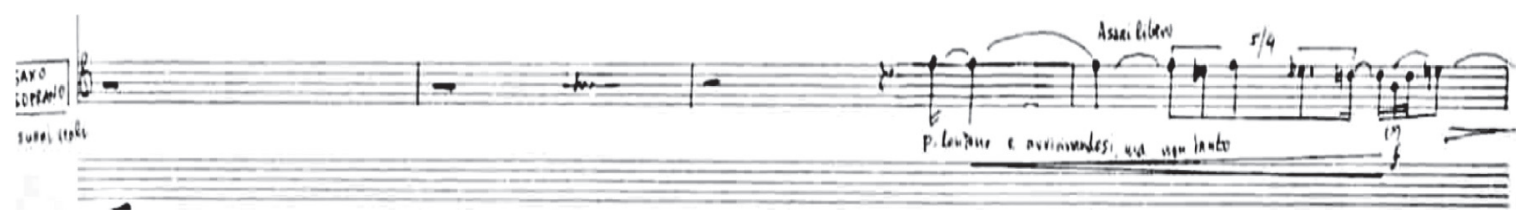

Fig. 9. Primera intervención del saxo soprano en la obra en el compás 117

13 PABLO, Luis de: Entrevista VI, Anexo VI, en: MARTINEZ GARCIA, 2011. 
El acompañamiento es de carácter hetereofónico. Esta técnica nos la comentó Luis de Pablo en una entrevista, y ya ha sido citada anteriormente en el capítulo VI ${ }^{14}$.
Todos los tempi se sitúan entre $\bullet=54$ y $\bullet=100$, excepto un vals a la francesa a $\bullet=120$ en el compás 164 . Desde el compás 181 al 212 aparece el intermedio de la orquesta para el cambio de escena, que esta vez es mucho más largo que el anterior.
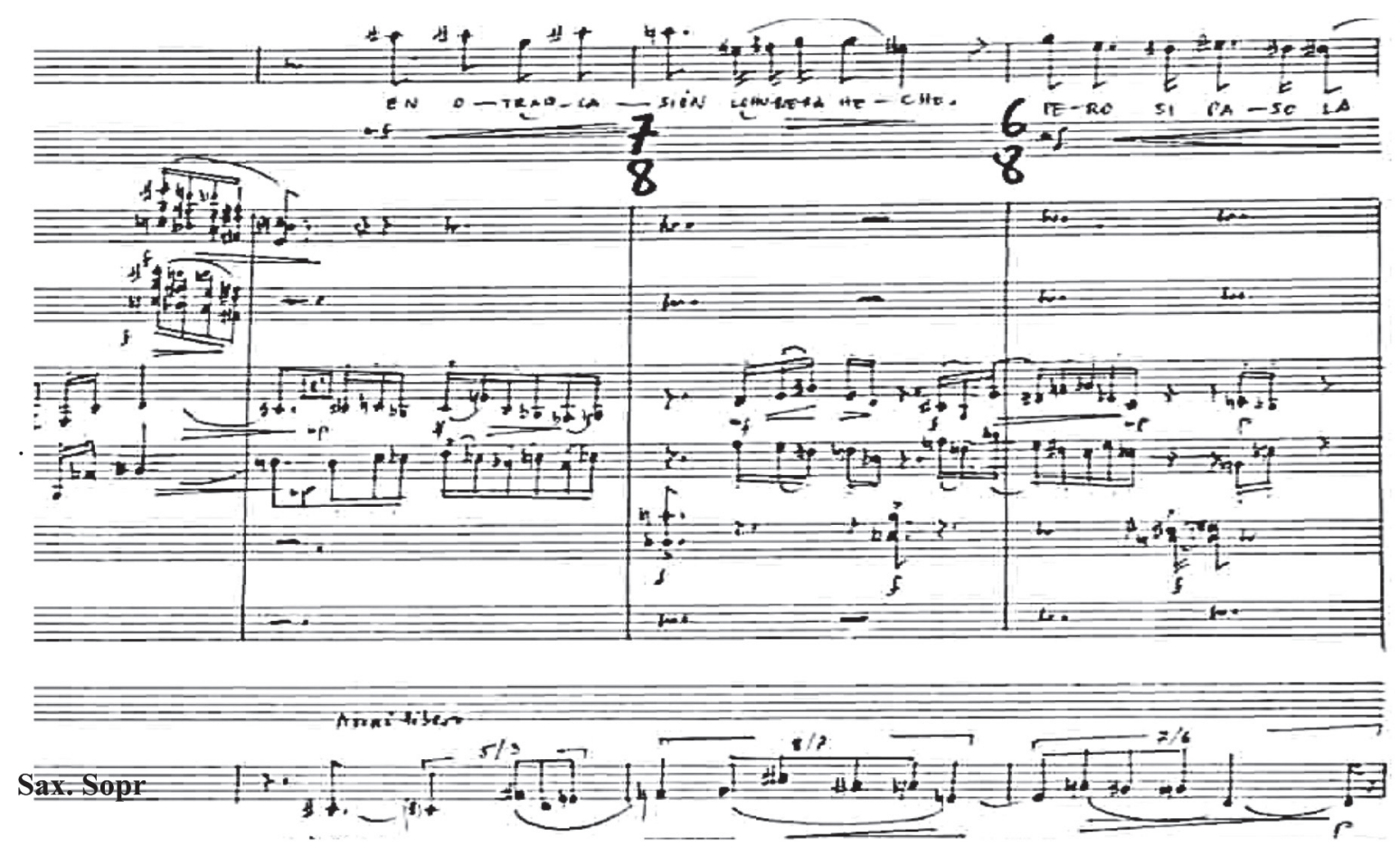

Fig. 10. Intervención del saxo soprano en los compases 142 a 144, acompañando la voz de Nazarie en disposición de heterofonía

La tercera escena transcurre en el comedor. La mesa está preparada para el desayuno. Nazarie entra por la izquierda y Simina por la derecha ${ }^{15}$. La escena es principalmente un diálogo entre Simina y Nazarie, aunque intervienen también la Sra. Moscu y Sanda.

La orquestación es más elaborada, buscando la intervención de pequeñas formaciones al principio, con una función de alternancia tímbrica, pero pronto aparecen unos unísonos repetidos por parte de toda la orquesta, principalmente sobre las notas fa sostenido y sol. Estos unísonos aparecen en las páginas 46, 47, 48 y 49. En la página 50 se resuelve

14 “[...] una línea melódica en el registro grave de la orquesta... que va haciendo lo mismo que otra, en el mismo registro, que no es exactamente lo mismo, sino que hay desfase" [PABLO, Luis de: Entrevista $V$, Anexo V, en: MARTINEZ GARCIA, 2011].

15 PABLO COSTALES, 2001: 27. esta tensión después de una intervención de Simina en un tutti fortísimo en unísono en $f a$ sostenido.

Según narra José Luis Téllez en el programa del estreno, las notas musicales podrían estar asociadas a personajes ${ }^{16}$ :

La presencia ausente y las sucesivas materializaciones de esta enigmática mujer se asocian de modo inequívoco al sol natural, y ocasionalmente a su cuarta, do natural (que cambia a re en la última escena), que se escuchan simultáneamente en la cuerda grave en el instante que Simina pronuncia su nombre por vez primera al final de la escena que inaugura la obra... Sol será la nota con que Egor identifique el perfume de violetas de la mujer. [...]

16 TÉLLEZ, 2001: 52-65, y 57. 
El compositor desmiente dicha teoría, que sí ha sido aplicada a óperas anteriores, pero no en ésta:

En Kiu sí hay un predominio no tanto de un intervalo cuanto un predominio de alturas. Los personajes tienen una altura predominante. Por ejemplo, el protagonista Simón pues es un si, quizá por el nombre que tiene ¿verdad?, Foster es un sol, Holmes es un do, y así sucesivamente. Esto no sucede en La señorita Cristina ${ }^{17}$.
El saxofón barítono aparece en el compás 40, y además el saxofón alto tiene dos intervenciones en las páginas 47 y 48 (Fig. 11). El empleo del saxo en este tiempo transcurre en cortas intervenciones que se añaden al grupo de viento principalmente, o en algún caso de manera aislada, proporcionando colorido tímbrico en determinados momentos.

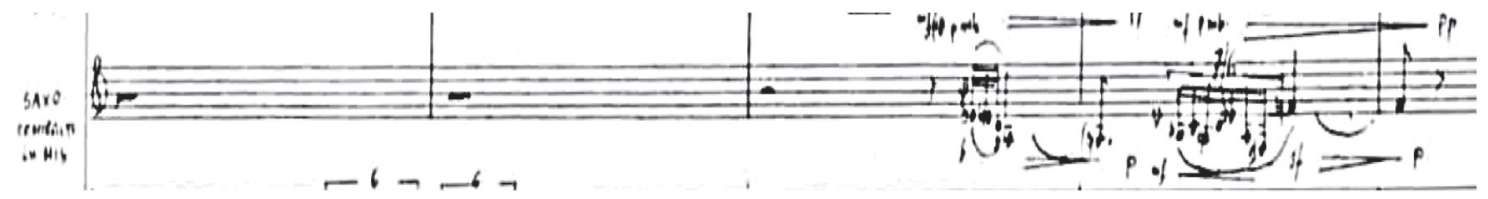

Fig. 11. Intervención del saxo alto en la página 47

Todos los tempi se sitúan entre $\bullet=76$ a $\bullet=92$. Cuando la subdivisión es ternaria, los tiempos oscilan entre.$=60 \mathrm{a}$ . = 100. El intermedio al final de este acto está en la página 51 y sólo tiene 22 compases de duración.

La cuarta escena tiene lugar en la habitación de Egor, es de noche y están en escena Egor y Nazarie. Esta escena, como en la segunda, transcurre con un diálogo entre los citados personajes. La orquestación de la pieza es más densa, las dinámicas más altas y la tensión va in crescendo hacia el último acorde de la página 82 . No hay intermedio ${ }^{18}$, y el suspense con el que termina el libreto en este acto se mantiene hasta el siguiente.

Los saxos tienen una participación destacada en esta escena, principalmente el barítono, cumpliendo la función de la Cristina omnipresente que el compositor nos ha comentado, y que comienza en el compás 39 (Fig. 12 ).

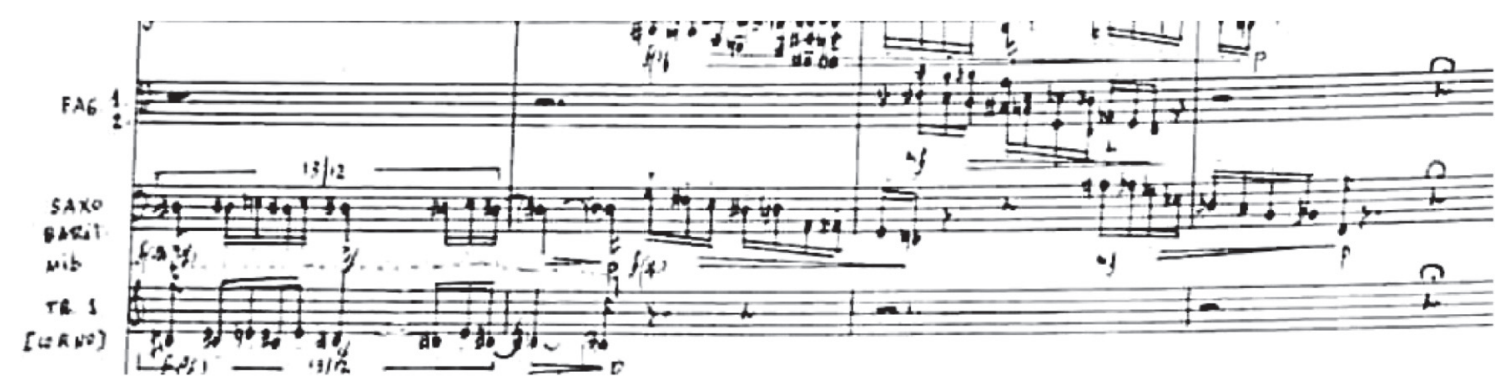

Fig. 12. Inicio del saxo barítono en el compás 39

17 PABLO, Luis de: Entrevista VI, Anexo VI, en: MARTINEZ GARCIA, 2011.
18 La falta de intermedio, se debe al descanso entre acto y acto. 
En el agitato que comienza en el compás 159, el barítono también tiene una participación importante: en un tiempo de $\bullet=92$ a ritmo de semicorcheas aparecen unas evo- luciones en escalas alternadas y el barítono participa en este diseño con el viento madera (Fig. 13).

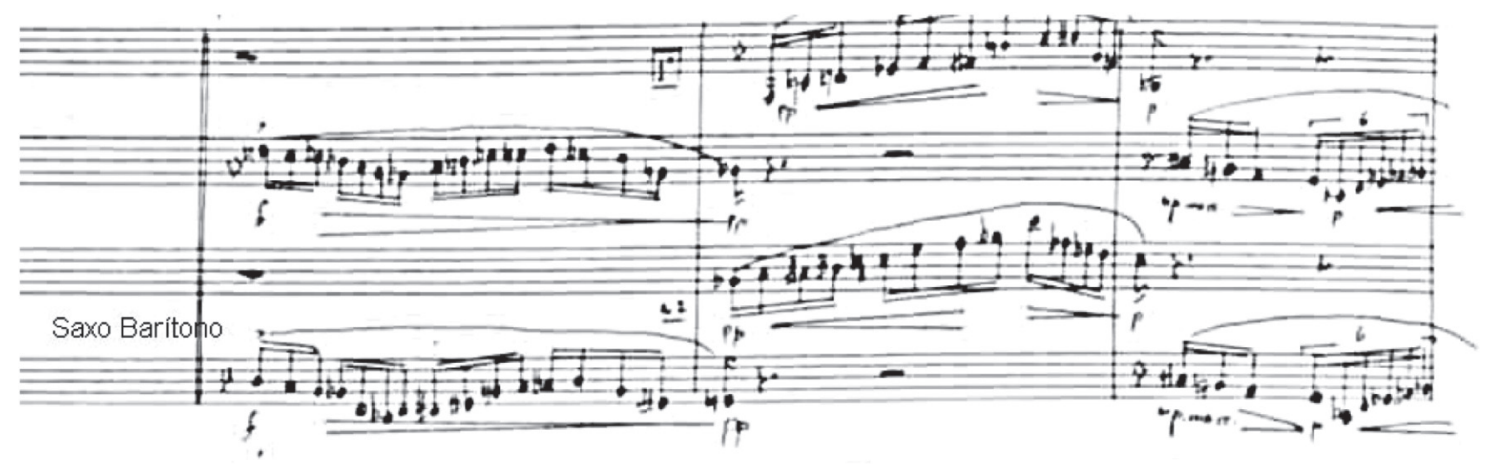

Fig. 13. Intervención del saxo barítono en el compás 159

Desde el compás 186 hasta el 201 es el saxo soprano el que participa, primero junto con las trompetas a trío, siendo protagonista en los tres últimos compases de esta intervención, que es la última en el transcurso de este acto (Fig. 14).

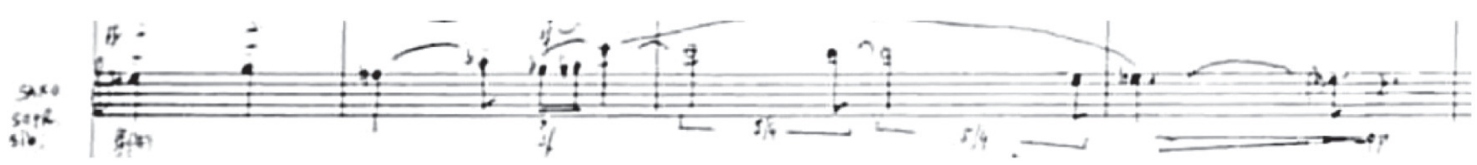

Fig. 14. Intervención del saxo soprano en el compás 201

Todos los metrónomos se sitúan entre $\bullet=72$ a $\bullet=$ 112. Cuando la subdivisión es ternaria, los tiempos oscilan entre $\cdot=60 \mathrm{a} \cdot=92$. El punto de máxima tensión dramática transcurre desde los compases 159 a 200, y precisamente el momento más fuerte está ubicado entre los compases 192 y 196, donde acabamos de comentar que el saxo soprano hace un trío con las trompetas. Después se va disolviendo todo hasta un solo de clarinete bajo en el compás 203, que cierra la sección. Esta tensión coincide con la tensión dramática en el momento que Nazarie narra a Egor lo acaecido con la muerte de La señorita Cristina.
A continuación, la última sección de la escena de 52 compases está más descargada musicalmente, porque cuenta el desenlace macabro de la muerte de la protagonista, Cristina, hecho que aconteció años atrás. Pero otra vez aparecen los unísonos con las mismas notas recurrentes en toda la obra, y precisamente la última intervención de la orquesta transcurre en un unísono $f a$ sostenido que resuelve en un fortísimo y corto sol (Fig. 15). 


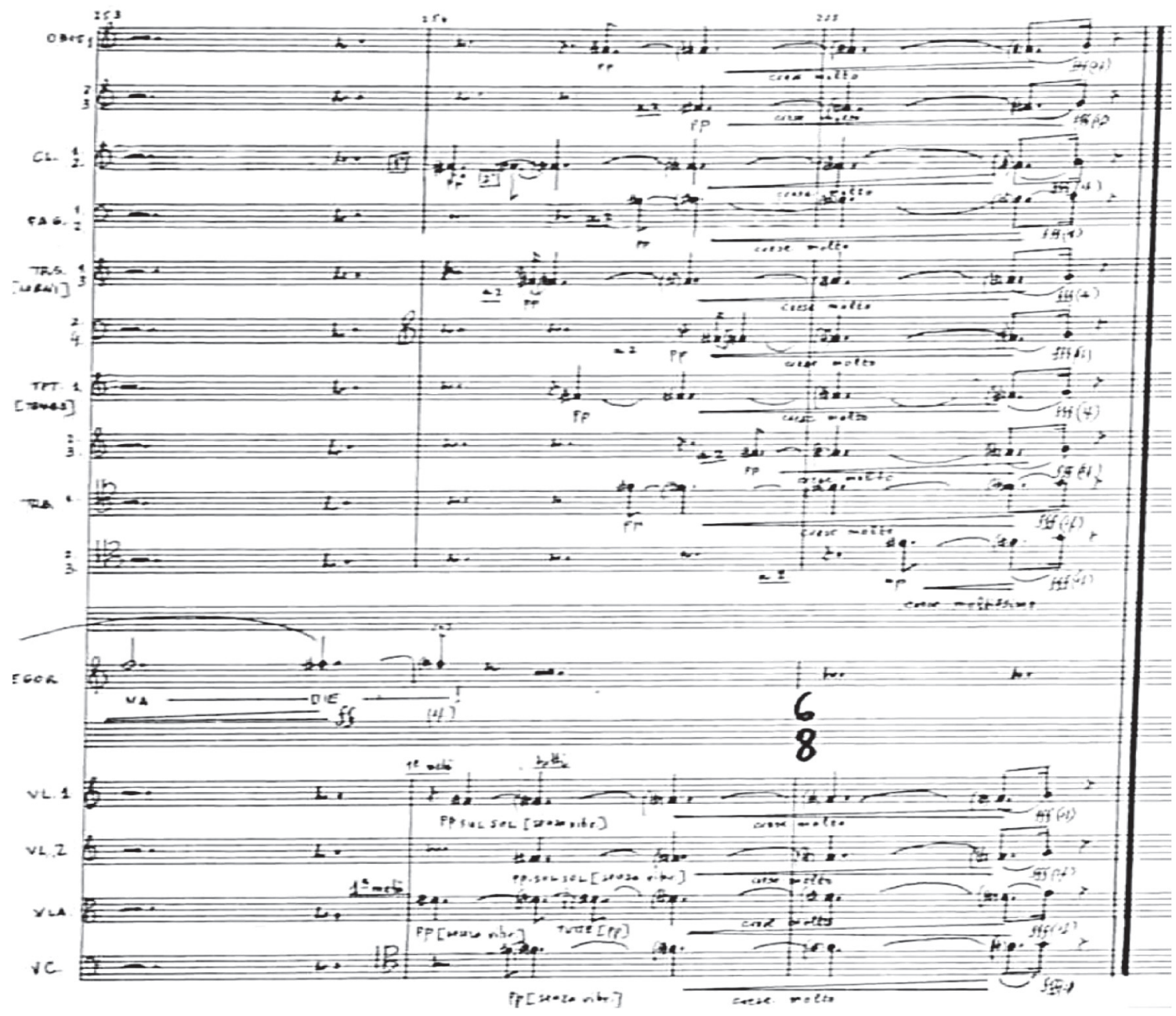

Fig. 15. Acorde final del primer acto

Preguntado el autor sobre la recurrencia de los unísonos a los momentos de mayor tensión, responde lo siguiente:

¡Ah, sí! Bueno eso es que son esenciales, son cosas que he utilizado y seguiré utilizando por razones... iQue no son razones! Eso es que en un momento determinado necesitas enfatizar una cosa y la única manera de enfatizarla es o bien servirte de un unísono o bien de octavas. En el arranque del Concierto de violonchelo, después de dos minutos más o menos, hay un unísono de casi toda la orquesta en do natural. Es la única nota que faltaba para toda una estructura que antes se ha oído, y para completarla la dejo sola ${ }^{19}$.

Este final en suspense obedece a necesidades dramáticas del libreto, que, recordemos, es del propio Luis de Pablo. Precisamente, el acto termina después que Nazarie cuenta cómo fue la muerte de la señorita Cristina (aunque nunca se encontró el cadáver), y el libreto cierra el acto con $^{20}$ :

19 PABLO, Luis de: Entrevista VI, Anexo VI, en: MARTINEZ GARCIA, 2011

20 PABLO COSTALES, 2001: 30. 
(PAUSA. NAZARIE MIRA POR LA VENTANA: LA NOCHE EN EL JARDÍN. ATERRORIZADO SEÑALA ALGO FUERA).

NAZARIE

¡Mire! Algo viene por allí...

EGOR

(MUY ROTUNDO Y ENÉRGICO)

¡No viene nada ni nadie!
El segundo acto tiene tres escenas, y la primera de ellas transcurre en la habitación de Egor. Envuelto en un ambiente onírico se le aparece Radu, antiguo compañero suyo de colegio que murió en un accidente, para prevenirle sobre Cristina. Será la escena más larga, en la que Cristina quiere hacerle comprende a Egor que le ha elegido como esposo.

Esquema formal, ${ }^{\circ}$ acto.

\begin{tabular}{|c|c|c|}
\hline Escena 1 & Escena 2 & Escena 3 \\
\hline $\begin{array}{l}\text { Aparición de Cristina, es la escena } \\
\text { de mayor duración. Introducción } \\
\text { de la orquesta de } 12 \text { compases. La } \\
\text { escena es la más larga y también } \\
\text { el intermedio de } 42 \text { compases de } \\
\text { duración. }\end{array}$ & $\begin{array}{l}\text { Sanda en su habitación enferma. } \\
\text { En esta escena aparece muy poco el } \\
\text { saxo. Únicamente el saxo barítono } \\
\text { efectúa un pequeño solo entre los } \\
\text { compases } 203 \text { a } 208 \text {. } \\
\text { No hay prácticamente intermedio en } \\
\text { esta escena. }\end{array}$ & $\begin{array}{l}\text { Larga introducción de } 55 \text { compases (telón } \\
\text { bajado). } \\
\text { La escena transcurre en la habitación de } \\
\text { Egor, donde se aparece Cristina e intenta } \\
\text { seducir a Egor. La mayor participación } \\
\text { del saxo hasta el momento en la obra e } \\
\text { importantes solos de barítono y alto. }\end{array}$ \\
\hline 331 & 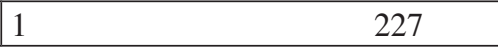 & $\begin{array}{ll}16 \\
\end{array}$ \\
\hline Compás & $\mathrm{a}$ & 874 \\
\hline
\end{tabular}

El acto se inicia con una introducción corta de doce compases a cargo de la cuerda de la orquesta como en el primer acto. En los compases once y doce se agregan flautas y flautín, que son los que toman el discurso melódico al inicio de la escena. La introducción comienza con una superposición de agregados donde predomina la nota sol, y ese polo armónico se mantiene durante toda la introducción (Fig. 16).

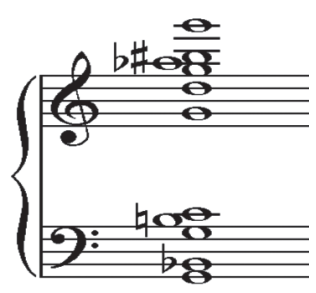

Fig. 16. Acorde inicial a cargo de la cuerda

Rítmicamente, la escritura fluye de la subdivisión binaria a la ternaria en función del discurso melódico o del fraseo de las voces. Ésta es una técnica constante en Luis de Pablo. Todos los tiempos se sitúan entre $\bullet=54 \mathrm{a} \bullet=72$, pero cuando la subdivisión es ternaria los tiempos oscilan entre

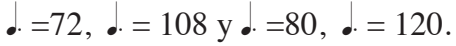

El primer punto de tensión ocurre en el compás 64, donde participa también el saxo barítono (Fig. 17). Es el momento en el que aparece Cristina.

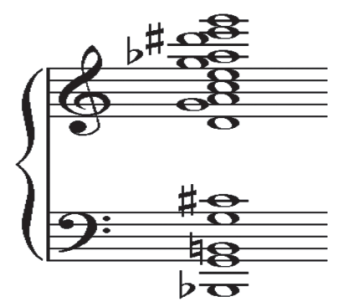

Fig. 17. Acorde en el compás 64 del segundo acto

Hay dos secciones centrales donde la música y la acción manifiestan más tensión, y que coinciden con las dos intervenciones más largas y apasionadas de Cristina. En ellas, los compases de amalgama y las figuraciones rápidas están presentes. En la primera, del compás 118 al 153, el tempo marcado es $\bullet=72$ y $\bullet=108$. En la segunda oca- 
sión que interviene el personaje de Cristina, aparece esta orquestación entre los compases del 203 al 227 y del 263 al 285 , y el tempo llega a una máxima velocidad de $\bullet=80$, . $=120$.
El saxo barítono es el que utiliza en más ocasiones el compositor, durante todo el transcurso de la ópera. En este tiempo, en total son seis las participaciones del saxo, todo ello es debido a que en él interviene Cristina.

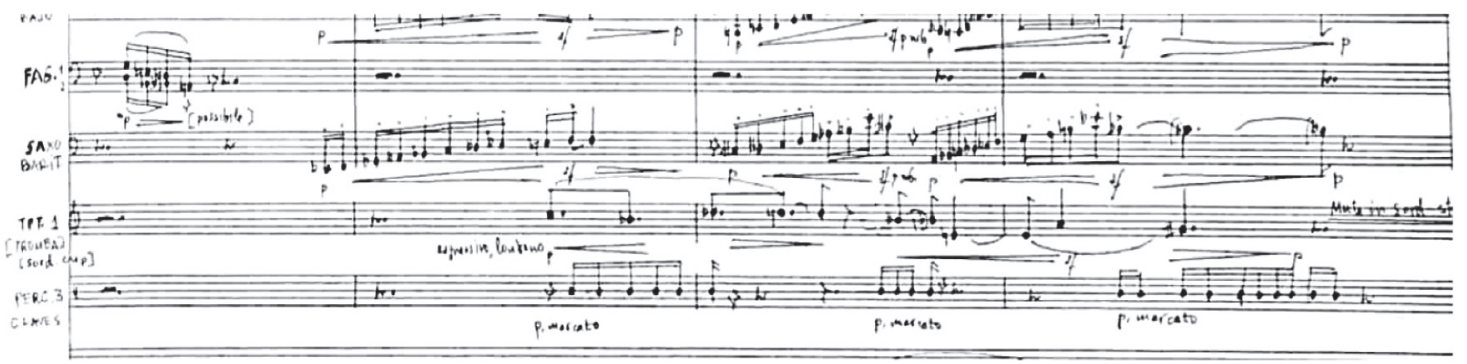

Fig. 18. Intervención del saxo barítono con el clarinete bajo, junto con otros instrumentos

En la primera de ellas, el saxo, efectúa unas evoluciones en forma de escalas a distancia de sextas y de séptima con junto con el clarinete bajo (Fig. 18). También ocurre algo parecido entre el trío de clarinete bajo, fagot y saxo barítono en el compás 212 (Fig. 19).

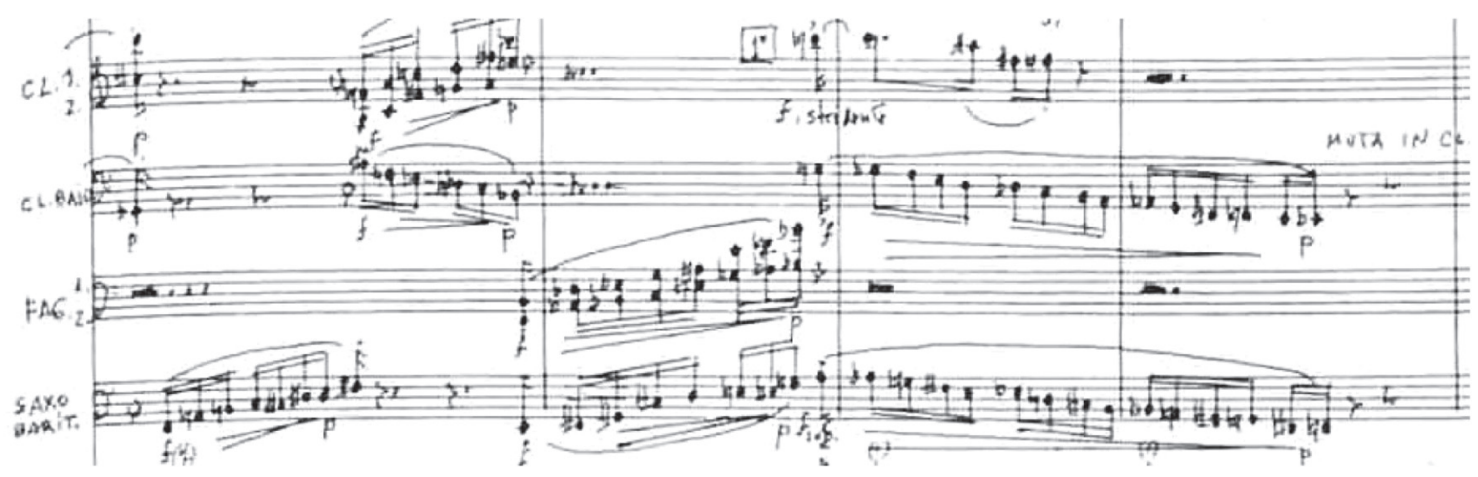

Fig. 19. Intervención del saxo barítono en el compás 212

En cambio, en el compás 280 la intervención del barítono (Fig. 20) es un pequeño solo que funciona como nexo entre el último punto de tensión y la despedida del personaje de Cristina, con lo que entramos en el intermedio final.

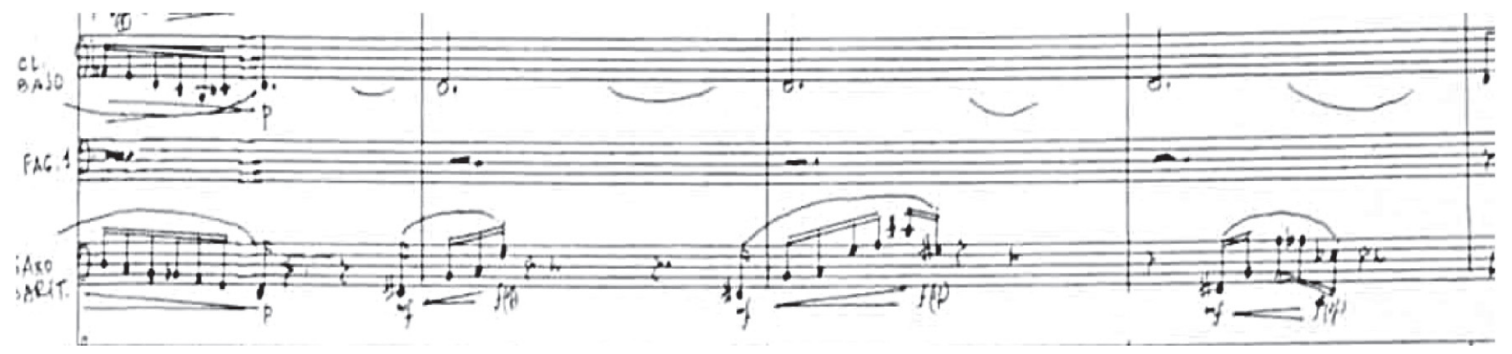

Fig. 20. Intervención del saxo barítono en el compás 280 
Esta escena es uno de los clímax de la obra, y justo en un momento en el que Cristina toca a Egor y entra una enorme mariposa nocturna, aparece el saxo barítono con el solo en el compás 280 (Fig. 20), con una intervención breve, pero dividida en tres cortas escalas rápidas.

El intermedio de 42 compases de duración es más relajado de densidad sonora. Participa sólo la parte de viento durante los 12 primeros compases y se agregan violas primero, cuerdas y percusión en un final de ambiente tonal, y que tiene muchos puntos de apoyo o polos armónicos, en el acorde de do como nota predominante y a veces en unísonos de la nota $d o$.

La segunda escena transcurre en la habitación de Sanda, que yace en el lecho enferma. Egor la acompaña, tam- bién la señora Moscu y Nazarie. Sanda y Egor coquetean, y la Madre de Sanda, la señora Moscu propone leer unos versos, mientras unos mosquitos interrumpen la lectura, Egor le dice a Sanda que la quiere y la señora Moscu despide la escena.

La escena se inicia con la señora Moscu agradeciendo casi a capella la presencia de Egor y Nazarie en la habitación de Sanda para visitarle. Únicamente dos violines con un agregado de cuarta justa acompañan a la Sra. Moscu. La orquesta se incorpora poco a poco. A partir del compás 6 aparece el resto de la cuerda, a la que en el compás 17 se añaden fagot, oboe y clarinete y un acorde de metales en el compás 22 y 23.

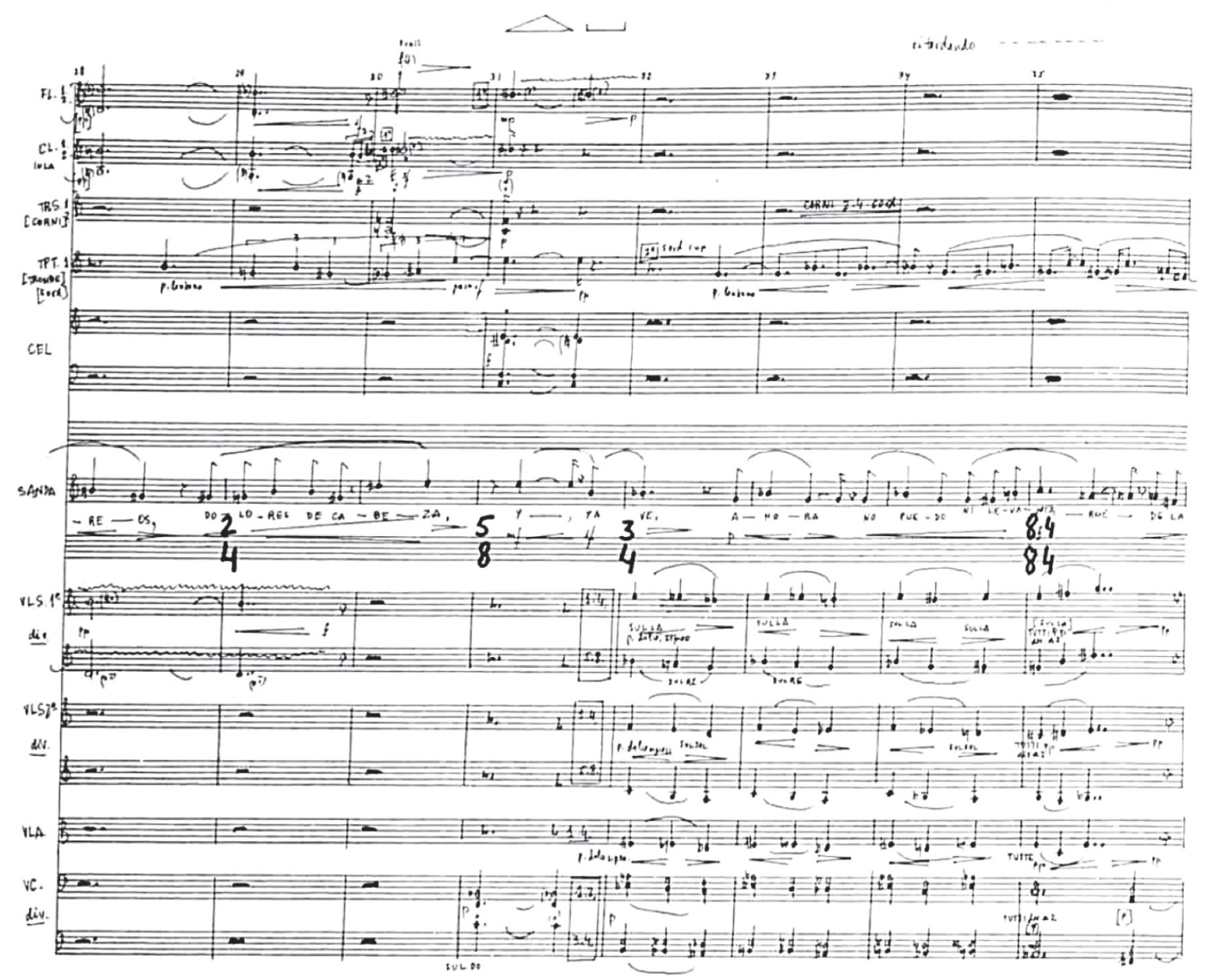

Fig. 21. Compases del 28 al 36 de la segunda escena del segundo acto

La cuerda es el conductor del sustrato sonoro en todo momento con un punto de tensión entre los compases 53 a 57, instante en el que Sanda le dice a Egor: "Tú eres el único que puede salvarme...", y la intervención de Egor se solapa con la de ella diciéndole: "No temas, Sanda. No te va a pasar nada. Yo estoy aquí a tu lado'1".

21 PABLO COSTALES, 2001: 33. 
La armonización de la cuerda, que es la conductora del discurso en esta escena, se mueve muy frecuentemente en cuartas, mientras que otros instrumentos colorean las voces, como es el caso de la trompeta y Sanda en el ejemplo que exponemos en la página siguiente (Fig. 21).

En el compás 67 un solo de violonchelo interrumpe el ambiente cariñoso entre Sanda y Egor y anticipa la atención que requiere la Señora Moscu, que propone leer unos versos de Alejandro Dumas y de Mihail Eminescu: "Las finas cuerdas de mi pecho por tu amor me lastiman, tus ojos me hacen daño y tu mirar me quema ${ }^{22}$ ".

Los tiempos de la escena fluyen entre $\bullet=56 \mathrm{y} \bullet=120$. La irrupción de los mosquitos, que interrumpen la lectura de la Sra. Moscu, implica el momento de mayor velocidad en el metrónomo y de la escritura en notas más rápidas, ya que es el punto culminante de la escena. Es el momento en el que Egor consigue declararle su amor a Sanda. El saxofón barítono aparece en esta escena en el compás 177, pero con muy pocas intervenciones, ya que Cristina no participa en esta escena. La más destacable es un solo entre los compases 203 y 208 (Fig. 22), justo cuando la señora Moscu habla de los mosquitos, exclama: "¡Ya nada nos queda... 23!" (Suena

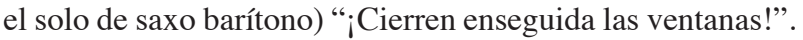
El compositor sugiere que en ese momento la Sra. Moscu piensa en la señorita Cristina, que realmente es la culpable de todo.

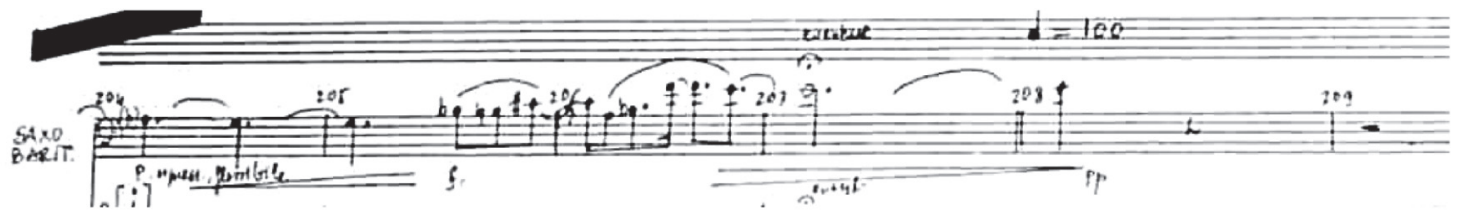

Fig. 22. Solo de saxo barítono del 204 a 208

La escena termina con una pequeña coda de la orquesta de 7 compases. Poco a poco desaparecen todos los instrumentos, quedándose solas las ocarinas en un acorde que da fin a la escena. No hay intermedio en esta escena porque una larga introducción en la siguiente reportará esta función necesaria para los cambios de decorados.

La tercera escena transcurre en la habitación de Egor. Cristina quiere que Egor baile con ella, y éste la rechaza, lo que produce la ira de Cristina. Esta escena tiene una dedicatoria a la Universidad Complutense, por lo que pensamos que haya podido ser interpretada como pieza de concierto, y le preguntamos al autor al respecto:

Esa escena está dedicada a la Universidad Complutense por una razón muy sencilla: porque en ese momento la Universidad nos hizo Doctores Honoris Causa a Cristóbal, a Carmelo, a Tomás y a mí. Con este motivo se hizo un concierto con cuatro obras que nos pidieron y yo les dije que lo sentía mucho, pero no podía hacer nada nuevo porque estaba hasta aquí de trabajo debido a la ópera, pero que con mucho gusto les regalaba esta escena. Y esa escena pues se tocó y se grabó, está grabada en disco con las otras tres obras. Como también se grabó la escena de Simina en el último acto, la que precede al

22 PABLO COSTALES, 2001: 33. final, que también lo tienes ahí. Estos dos fragmentos que te he dicho los tienes grabados en disco... Que podemos oírlos ahora si quieres... Son cada uno de la duración de una escena de ópera, unos diez o doce minutos ${ }^{24}$.

La orquesta realiza una introducción de 55 compases a telón bajado y la primera intervención de Egor se produce en el compás 68. El inicio corre a cargo de los violonchelos y contrabajos que constantemente sustentan el discurso con algunos puntos de color por parte de clarinetes, fagots y viento metal. A partir del compás 29 se incrementa la densidad y se añaden los violines y gradualmente el resto de plantilla de la orquesta.

Los tiempos de la escena oscilan casi siempre entre $\bullet=100 \mathrm{y} \bullet=120$, con algunos pequeños fragmentos más lentos, pero de corta duración que están a $\bullet=54$ y $\bullet=42$. La segunda sección del tiempo es cuando se inicia la acción dramática y va desde el compás 65 al 100. Ésta sección corresponde únicamente a la primera aparición de Cristina, en la que se abraza a Egor, precedida de una conversación de Egor con Radu.

23 PABLO COSTALES, 2001: 34.

24 PABLO, Luis de: Entrevista VI, Anexo VI, en: MARTINEZ GARCIA, 2011. 
Un fragmento de arpa y cuerda de 5 compases parece mostrar la sorpresa de Egor por la aparición de Cristina. Otra sección transcurre desde el compás 106 al 154, la cual se corresponde con otra parte de la acción en la que Cristina intenta embelesar a Egor. En esta sección aparecen los "steel drums" como timbre llamativo que a veces conversan con la cantante solista.

Una cuarta sección de la escena iría desde el compás 155 al 228, que terminará con la Negativa de Egor a amar a Cristina: “QQuiero a Sanda e imploro a Dios ${ }^{25}$ !" En ese momento, el tiempo se ralentiza y la contestación de Cristina se hace esperar durante sólo 14 compases.
Se inicia en el 242, donde comienza una larga intervención llena de ira en la que describe lo que le hubiera podido hacer, y predice que conseguirá que la ame.

El tiempo se ralentiza poco a poco, hasta llegar al momento más lento y triste de la escena, con un tiempo de - $=42$, "Pero a ti no quiero matarte, amor mío, te he elegido como esposo...26". El texto sigue hasta el final de la escena y no hay intermedio, puesto que termina el acto. El acorde final de este segundo acto lo constituye esta vez un unísono re que resuelve en un $m i$ bemol corto (Fig. 23).

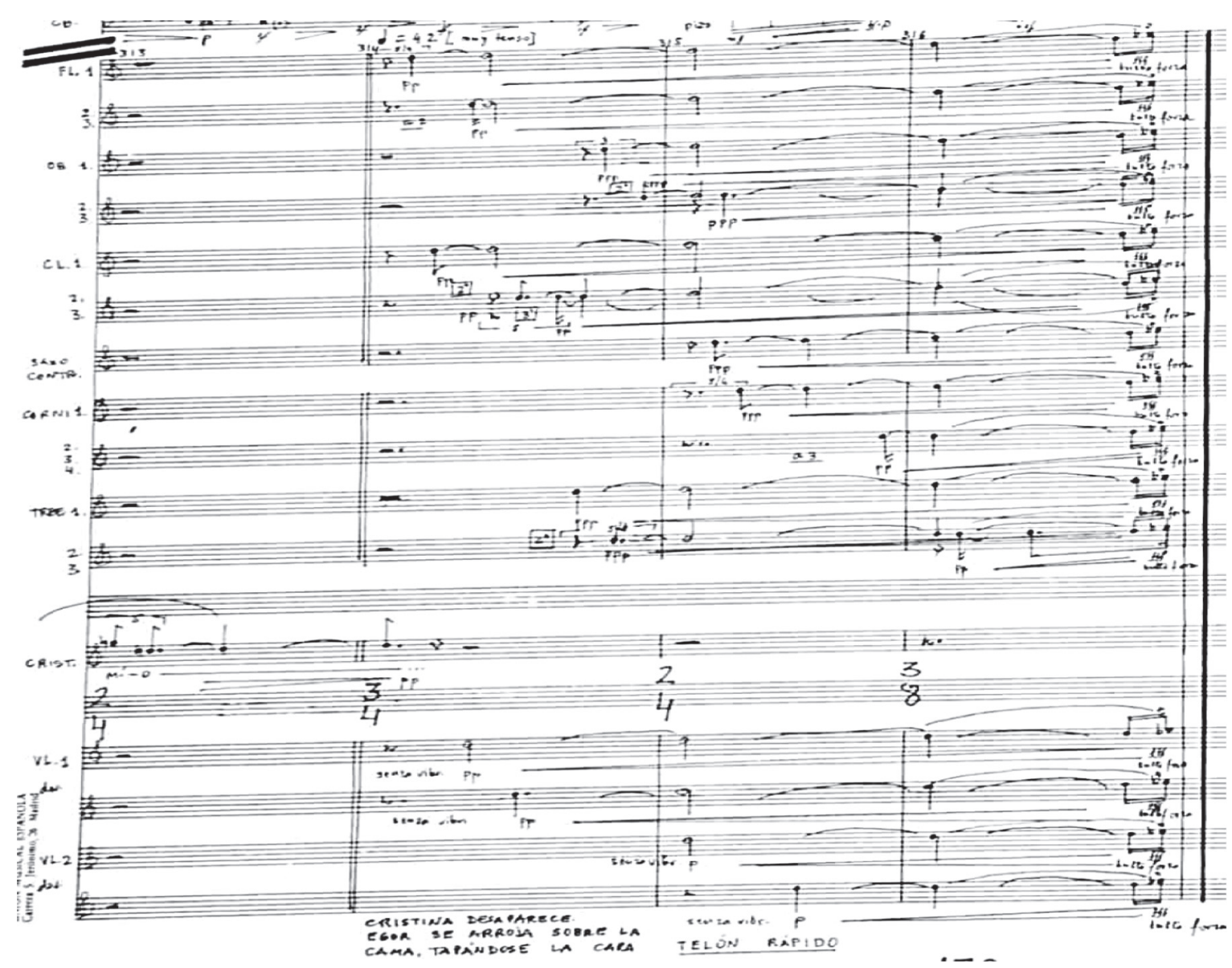

Fig. 23. Acorde final del segundo acto 
El saxofón barítono aparece muy pronto en el compás 14. El saxofón va a tener mucho protagonismo en esta escena, puesto que Cristina está presente (Fig. 24).

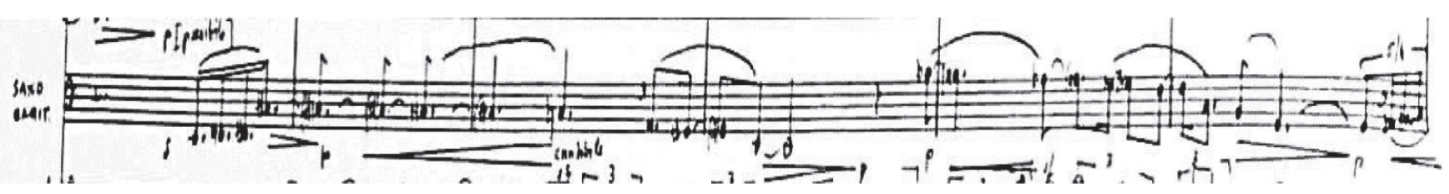

Fig. 24. Intervención del saxo barítono en el compás 14

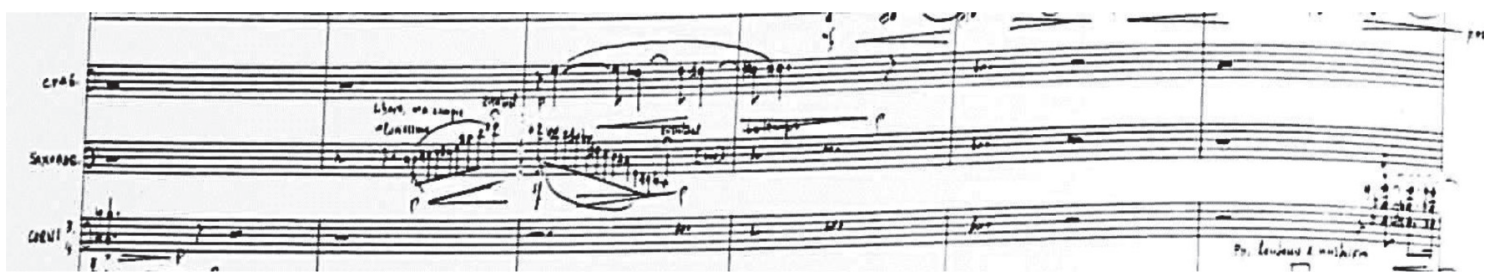

Fig. 25. El saxo barítono en el compás 85

Hay intervenciones como las del barítono en los compases 85 y 132, que son pequeños solos libres en forma de cadencia (Figs. 24-25-26).

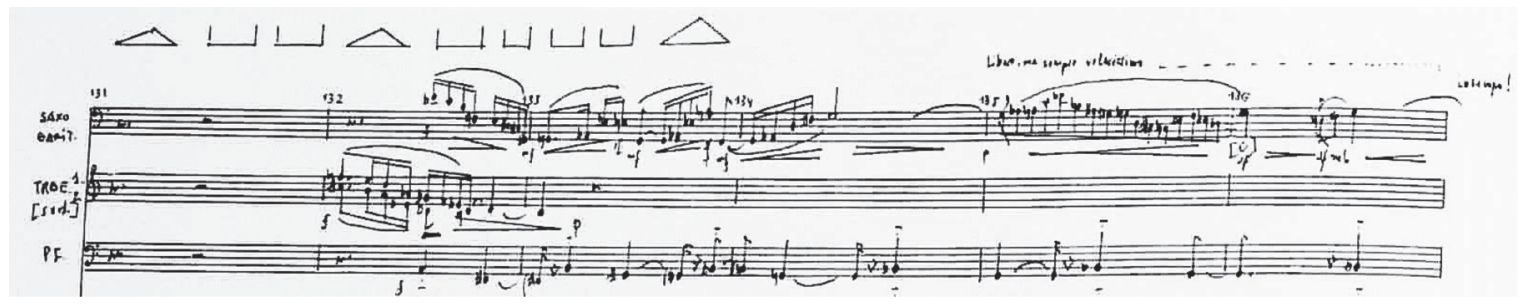

Fig. 26. El saxo barítono en el compás 132.

En este tiempo, el compositor utiliza el saxofón alto también (Fig. 27), ya que la tesitura prevista para los solos es demasiado aguda para el barítono.

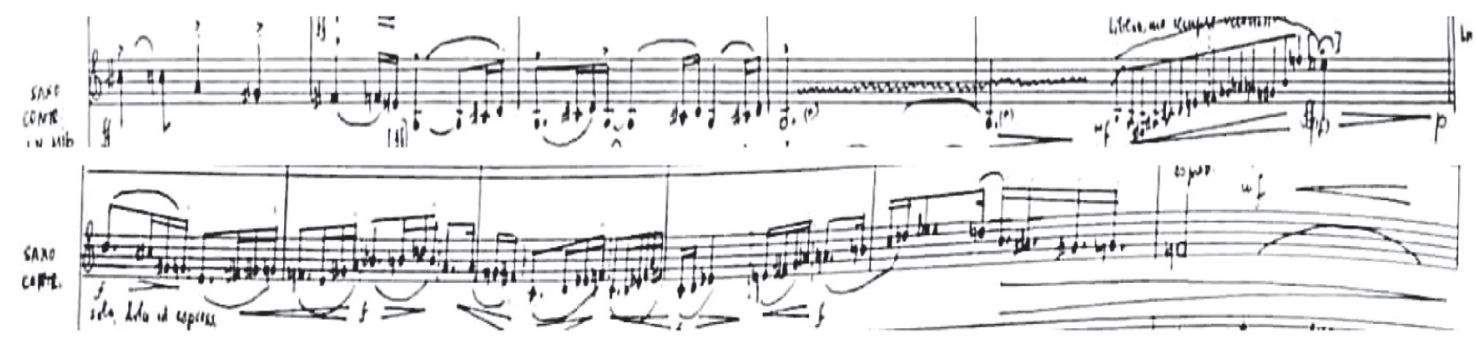

Fig. 27. El saxo alto en el compás 185 
Los fragmentos de estas intervenciones de saxofón barítono y alto en esta escena técnicamente son los más difíci- les de interpretar, y resultan muy interesantes para descifrar el lenguaje saxofonístico de Luis de Pablo.

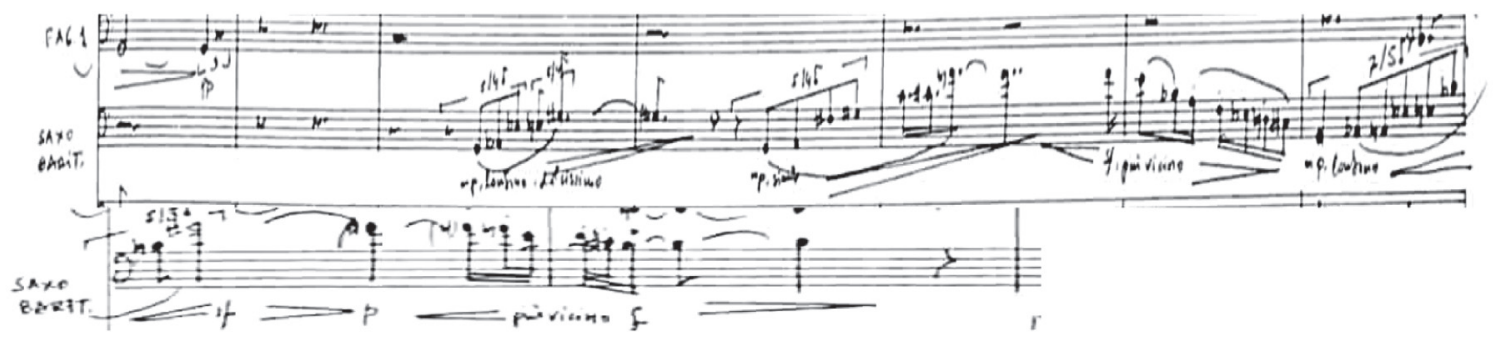

Fig. 28. Solo de saxo barítono desde el 243 a 249

En el caso del saxofón alto el registro sólo llega al do agudo $^{27}$ (Fig. 27), y en el caso del barítono llega al re agudo. Son pasajes rápidos y virtuosos, pero no son incómodos de digitación ni hay saltos importantes (Fig. 28).

El tercer acto, como el anterior, tiene tres escenas, pero se inicia con una introducción de la orquesta de 43 compases de duración. Los dos primeros acordes, a distancias de terceras y cuartas, están dispuestos por el sistema de agregados propio del autor. Se mueven en un intervalo descendente de semitono en movimiento contrario al acorde re, $m i$ bemol en unísono con el que terminó el segundo acto (Fig. 29).
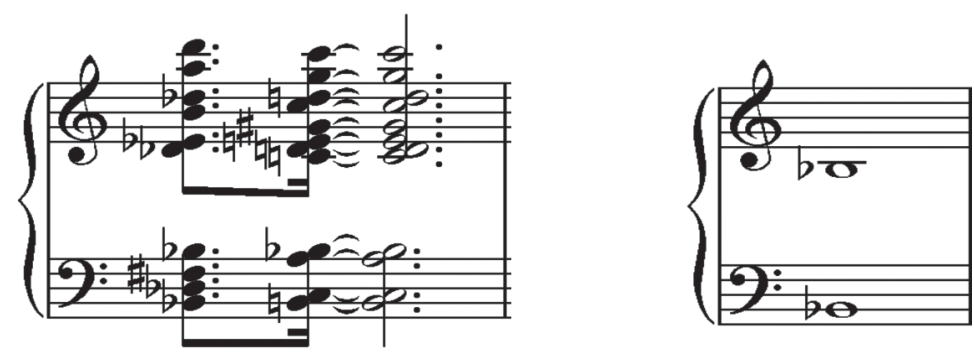

Fig. 29. Acordes de inicio del segundo acto, primero y cuarto compás

Es un modo de resolver la cadencia inconclusa con la que finaliza el segundo acto. Este acorde se mueve a un unisonó en octavas de si bemol al cuarto compás (Fig. 281). Los unísonos, serán frecuentes durante toda la primera escena, cuando las voces están dispuestas verticalmente en acordes. Es un recurso que emplea de modo habitual, como nos ha comentado el autor, con fines dramáticos.
27 Téngase en cuenta que el saxofón alto es un instrumento transpositor. El $m i$ bemol negra con calderón es un do agudo en el alto (Fig. 6). 


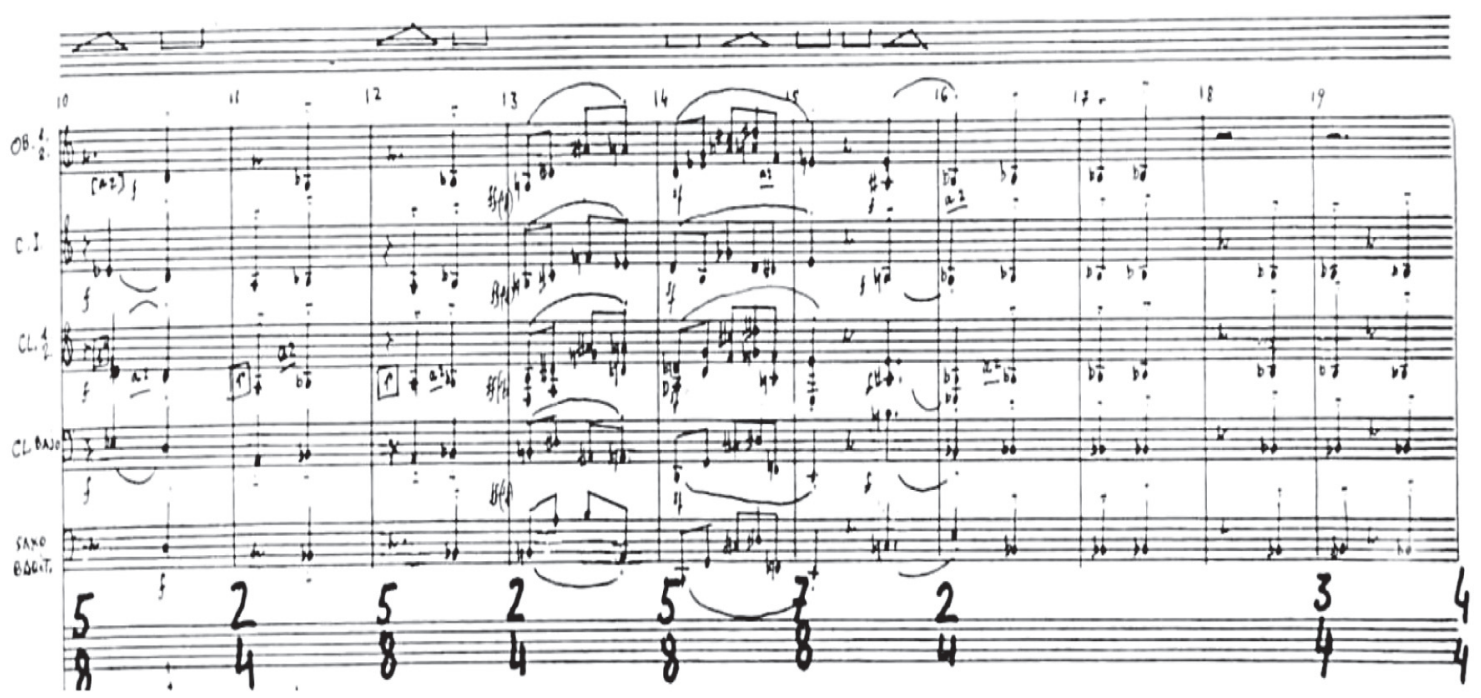

Fig. 30. Células melódicas al principio del tercer acto

Otra disposición habitual es que las voces se muevan en unísonos o en distancia de cuarta en células melódicas, que más adelante se sucederán desplazadas, a distancia de un compás, unas voces de otras (fig. 30).

Después de la introducción de la orquesta, comienza la primera escena en el compás 43 y transcurre en la habitación de Sanda. En esta escena Egor y Sanda se prometen, y en pos de proteger a Sanda de Cristina, Egor decide que deben marcharse inmediatamente de la hacienda. La escena es más rápida de lo habitual en el segundo acto, y se divide en tres secciones: la primera de ellas desde el compás 43 al 182. El tempo se mueve entre $\bullet=132, \bullet=96$, y en la acción lo que ocurre en esta sección es que la señora Moscu no encuentra a Sanda en su habitación, entra Egor y la encuentra sumida en un trance.

\section{Esquema formal, $3^{\circ}$ acto.}

\begin{tabular}{|c|c|c|}
\hline ESCENA 1 & Escena II & Escena III \\
\hline $\begin{array}{l}\text { Habitación de Sanda. } \\
\text { Introducción de } 43 \text { compases. } \\
\text { Participa el saxo barítono. } \\
\text { En esta escena se desarrolla un } \\
\text { dueto de amor entre Egor y Sanda y } \\
\text { aquel le promete cuidarla y deciden } \\
\text { marcharse de la casa. }\end{array}$ & $\begin{array}{l}\text { Sótano de la casa. Introducción de } \\
10 \text { compases. Las voces entran en } \\
\text { el undécimo compás. Egor y Simina } \\
\text { acaparan todo el argumento. Del } 229 \\
\text { al } 316 \text { hay una larga intervención de } \\
\text { la orquesta. }\end{array}$ & $\begin{array}{l}\text { Habitación de Egor y salón de baile. Se } \\
\text { divide en tres secciones: una primera en } \\
\text { la que Egor espera a Cristina, otra central } \\
\text { en la que hay un dueto de amor entre } \\
\text { ambos y una tercera de desenlace en la que } \\
\text { Cristina desaparece de su mundo vampírico } \\
\text { maldiciendo a Egor con una muerte joven, } \\
\text { por añoranza de ella. }\end{array}$ \\
\hline 292 & 316 & $\begin{array}{ll}1 & 407 \\
\end{array}$ \\
\hline 1 & $\mathrm{a}$ & 1015 \\
\hline
\end{tabular}

El saxofón a partir de la introducción participa poco, ya que en esta escena Cristina no está en el libreto (recordemos que éste personaje siempre está presente en la casa de algún modo). Suele dialogar en sus intervenciones con el clarinete bajo o discurrir al unísono con éste. Otras veces las intervenciones discurren en trío, añadiéndose el fagot, como en el ejemplo de la (Fig. 31). 


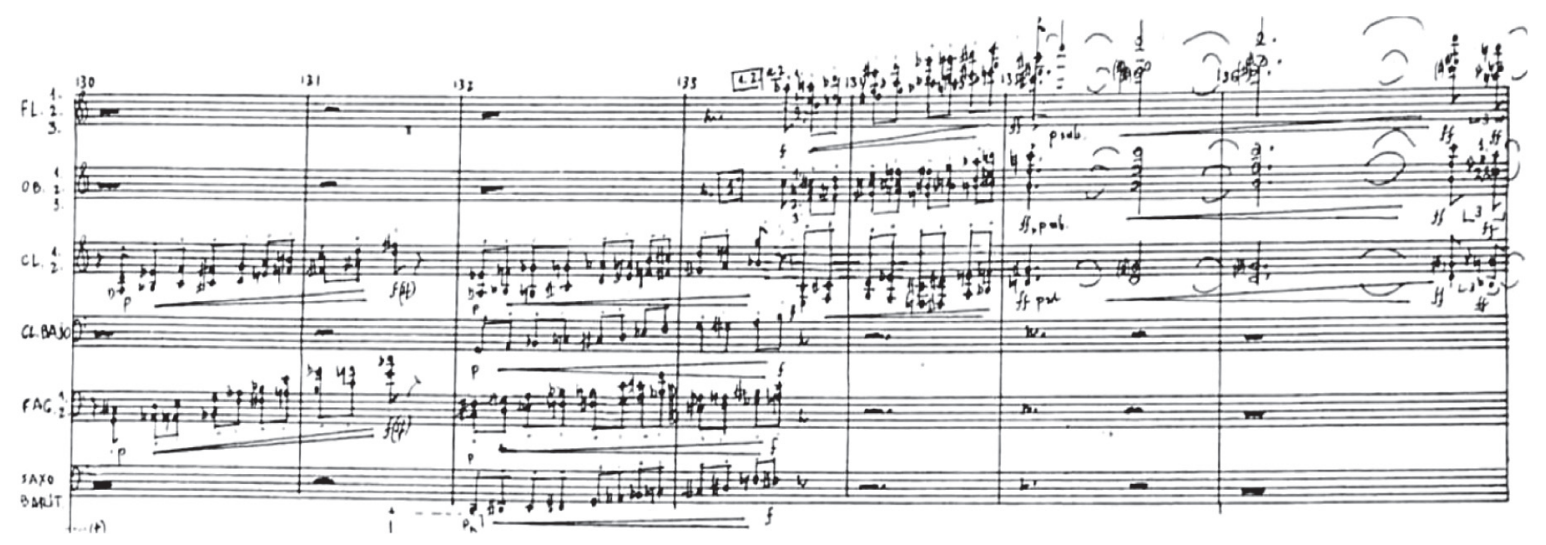

Fig. 31. Participación del saxo barítono en el compás 132

La segunda sección de la escena es un duetto de amor entre Egor y Sanda, después de que éste cierre la puerta con llave para estar solos, y termina cuando Egor la abraza y le promete defenderla. El dueto se mueve tanto en movimiento directo como en movimiento contrario, en frecuentes terceras e unísonos (Fig. 32). La tercera sección es el momento en el que Egor anuncia a la señora Moscu que se ha prometido con Sanda y ésta le pide que la defienda, por lo que deciden marcharse en ese momento. La instrumentación es menos densa, la sección es más corta y los unísonos son frecuentes en las notas si y sol y desemboca en un intermedio de 22 compases para cerrar la escena.

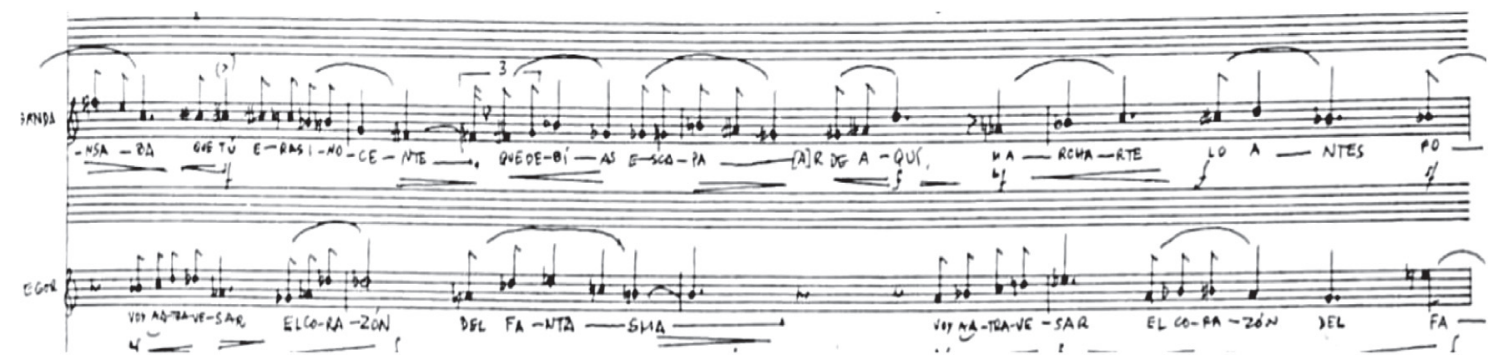

Fig. 32. Duetto de Egor y Sanda

Los tiempos son más lentos y oscilan entre $\bullet=50$ - =66. Participan mayoritariamente las flautas y ocarinas, con algún solo por parte de estas, junto con percusiones agudas (glockenspiel), celesta, trompetas y la sección de cuerda, iniciándose la segunda escena sin ningún acorde de preparación ni interrupción.
La segunda escena del tercer acto transcurre en: "Sótano de la casa. Lóbrego, techos bajos. Largos pasillos. Muchas viejas botellas cubiertas de polvo. Escena vacía. Entran Egor y Simina ${ }^{28}$ ".

Egor acompaña a Simina para coger una botella de vino en el sótano. La escena se divide en dos secciones principales y un largo interludio al final. 


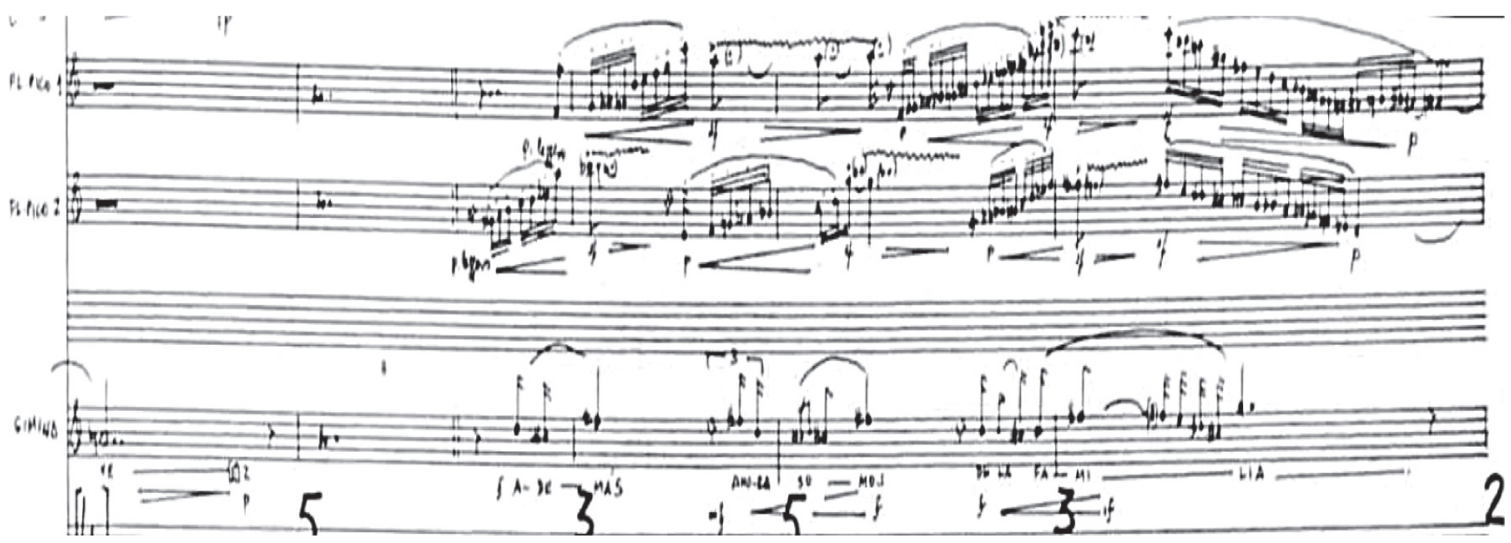

Fig. 33. Intervención de las flautas de pico junto con Simina

La primera sección se inicia tras 10 compases de introducción por un solo de flautas de pico, el cual es el instrumento que representa la personalidad de Simina. A continuación, ésta inicia una larga intervención que sirve para describir por qué Egor le acompaña al sótano. A partir del compás 28 se produce un diálogo entre flautas de pico y Simina hasta el compás 43 (Fig. 33), en el que Egor le interroga: “¿Por qué te envía tu madre al sótano si en el patio hay muchos criados? $?^{29}$ "

La segunda sección, la más prolongada, es aquella en la que Simina se convierte en una suerte de bruja y trata cruelmente a Egor. En realidad, todo es un ardid para distraer a Egor mientras muere Sanda. El saxo barítono participa varias veces en frases de dos a cuatro compases, pero sobre todo cuando Egor le pregunta: "Ella está aquí, ¿verdad?30"

Esta sección termina en el compás 229, donde cae el telón y se inicia un largo interludio de 87 compases antes del desenlace final en el tercer acto.
Los cambios de tempo son frecuentes, ensalzando el dramatismo del argumento y oscilan entre $\bullet=54 \mathrm{a} \bullet=132$, procurando un intercambio entre agitación y tensión, ya que es una escena muy trágica. La instrumentación es muy cambiante, con grupos rápidos y casi siempre ascendentes, buscando la tensión del registro agudo en los instrumentos de viento. .

Los pasajes tanto de los cantantes como de otros instrumentos, como a veces el saxo, están reforzados de un modo dramático. Así ocurre con el saxo barítono, que en el compás 199 su frase está apoyada con una métrica exacta por un tom-tom (Fig. 34). Es un momento de tensión en el que Simina le reprocha a Egor su cobardía. 


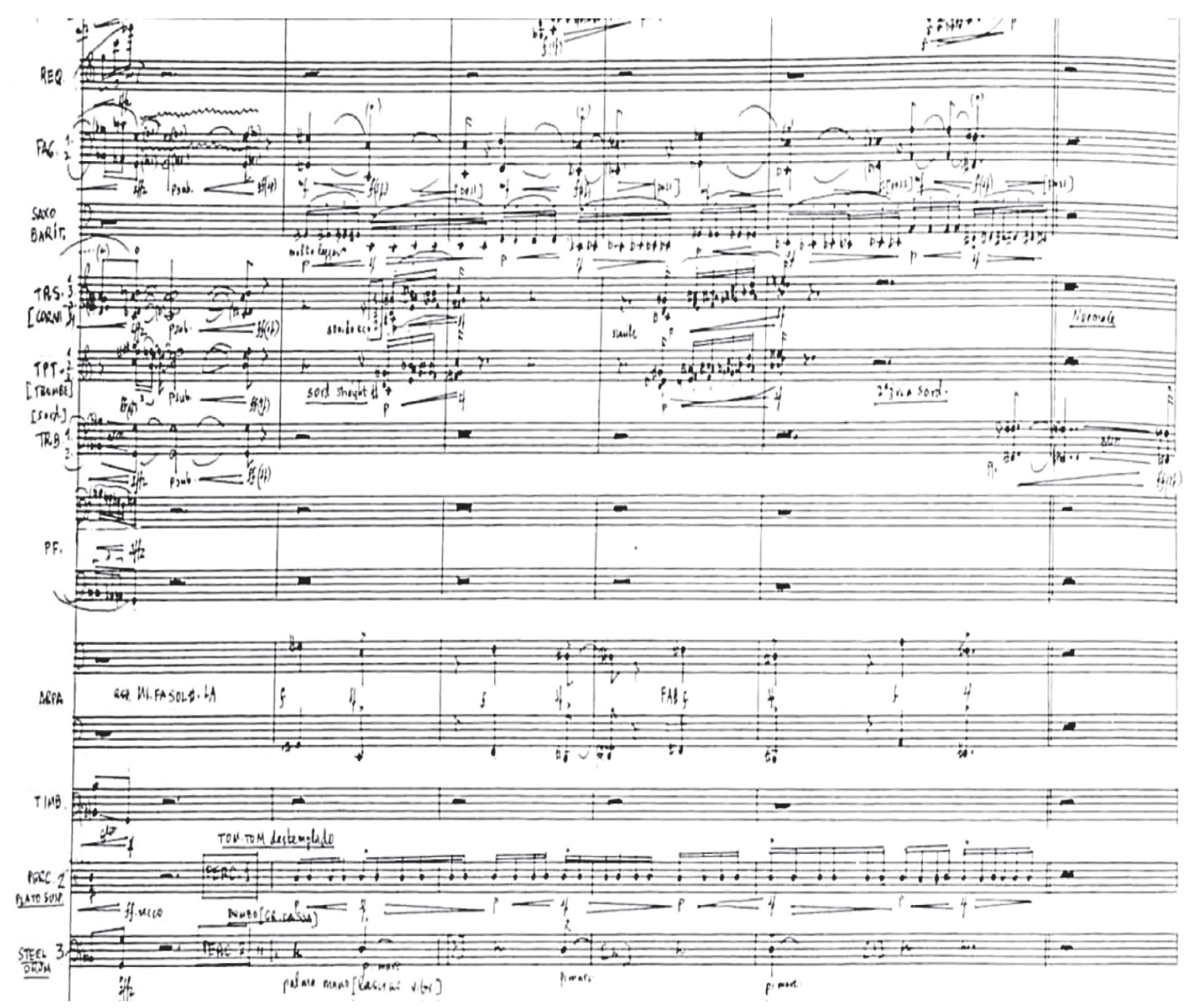

Fig. 34. Intervención del saxo barítono junto con el tom-tom en el compás 199 a 202

La cuerda se mueve entre acordes dispuestos como agregados y octavas, pero con el mismo nerviosismo que los vientos. El inicio del interludio se confía otra vez a Simina de una forma figurada mediante un solo de flautas de pico. El final del interludio desde el compás 290 se confía a la cuerda, con el añadido de dos solos, el primero de ellos de trompeta y el segundo y mucho más destacado del violín en el compás 295 (Fig. 35), cerrándose el interludio con un enigmático trino in crescendo de la cuerda con el que se abre el telón de la tercera escena. El saxofón no participa en el interludio. 


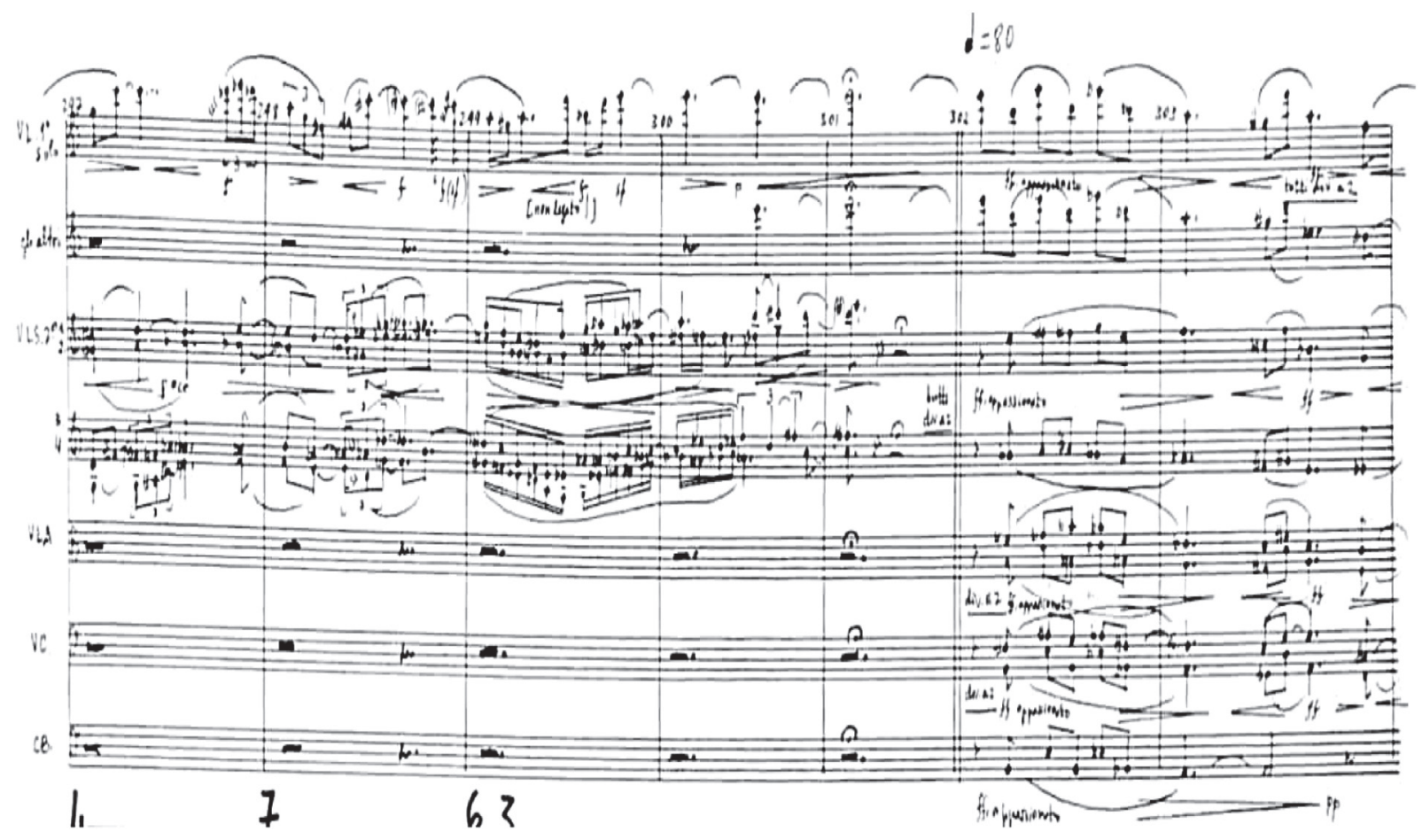

Fig. 35. Solo de violín al final del interludio

En la tercera escena se produce el desenlace con la participación casi exclusiva de Egor y Cristina: "Habitación de Egor. Ambiente Realista. Es de Noche, Egor solo"31.

La escena se inicia con un dúo de fagotes hasta el compás 17. Egor comienza a cantar en el compás 13. El monólogo de Egor, que está esperando la aparición de Cristina, se desarrolla hasta el compás 48 dudando entre la realidad y el sueño, entre la vida y la muerte. Este momento de duda está instrumentado por Luis de Pablo como si fuese una corta marcha fúnebre de ocho compases.

A continuación se oyen los pasos de Cristina, el tempo se acelera y aparece un solo de saxo barítono entre los compases 62 a 65 . La puerta se abre y unísono en octavas de la nota $f a$, que resuelve en un agregado con el sol como nota predominante, da paso a la aparición de Cristina en el compás 81 (Fig. 36). 


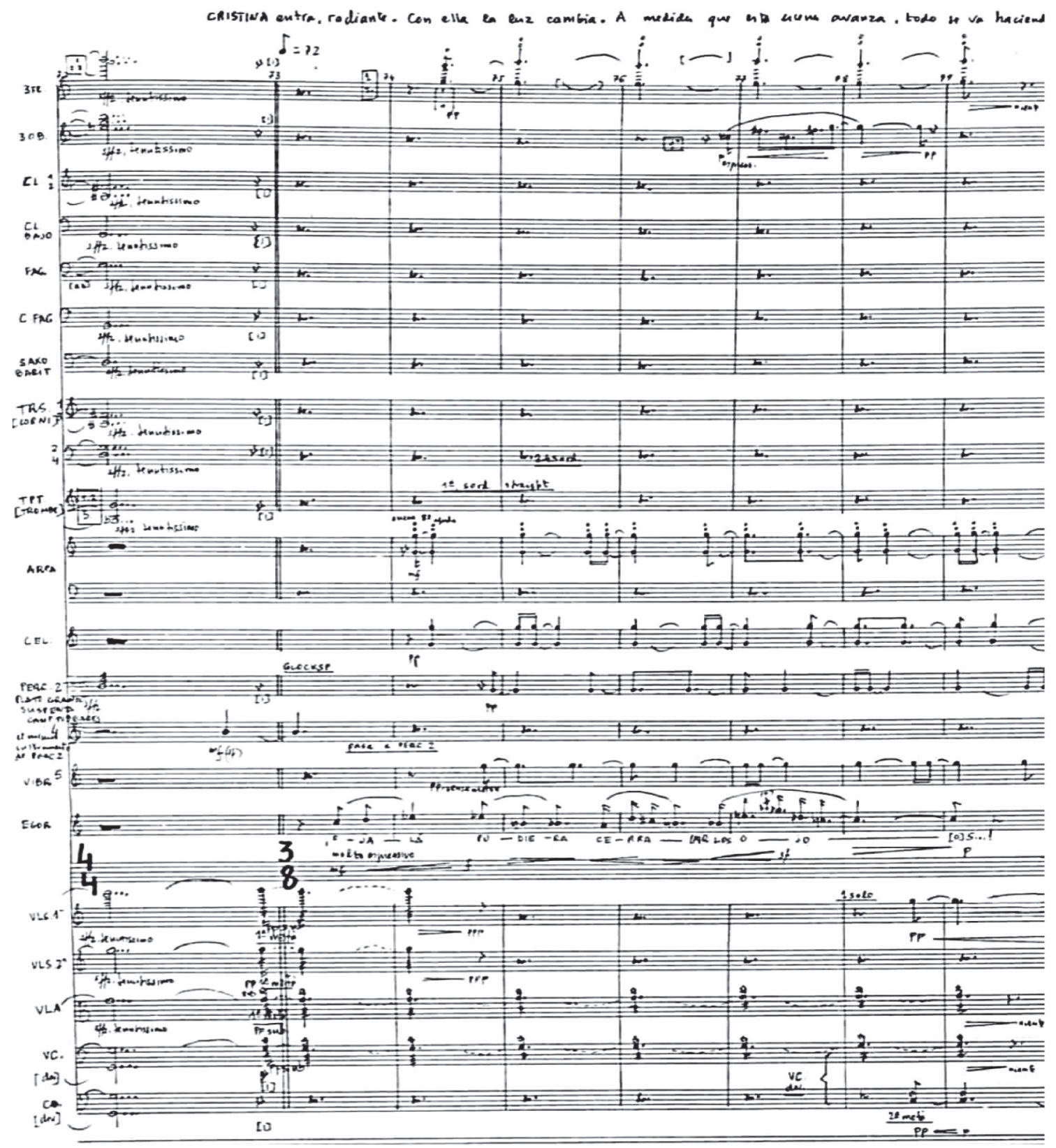

Fig. 36. Acorde en el compás 73. Entrada de Cristina

A partir de este momento, se inicia una segunda sección en la que se presenta uno de los instantes sustanciosos en cuanto a elaboración y longitud. Se trata del duetto entre Cristina y Egor (Figs. 37-38). Éste se desarrolla acompaña- dos solamente por la cuerda, desde el compás 116 al 222, oportunidad en la que se abrazan y Egor descubre la herida de Cristina, porque se mancha de sangre. 


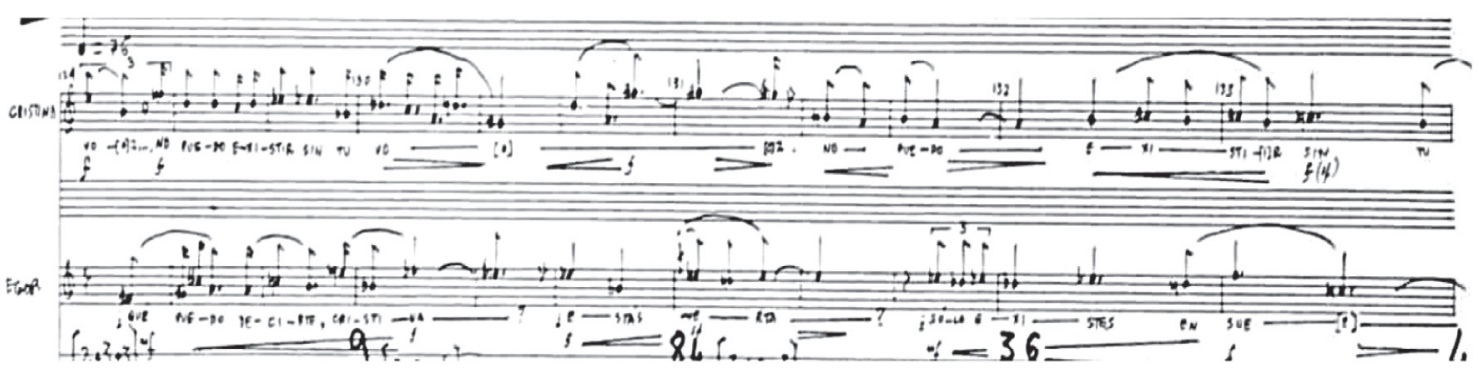

Fig. 37. Dueto de Cristina y Egor

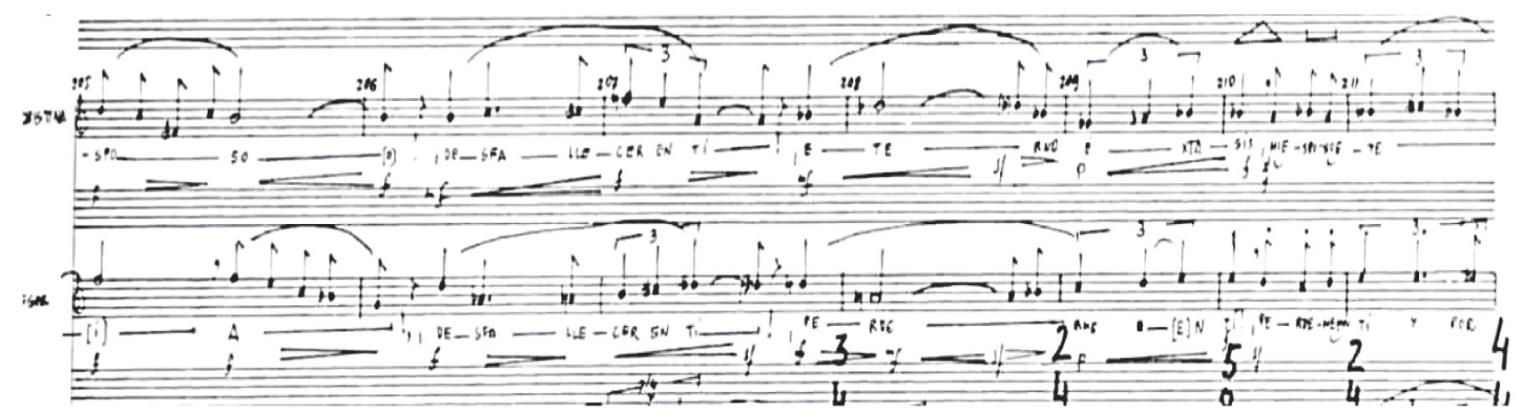

Fig. 38. Dueto de Cristina y Egor

En este punto se produce el máximo clímax en la obra, y la orquesta está compuesta por toda la cuerda, metales y percusión, destacando el empleo en esta ocasión, de los sonoramente incisivos "still drums".

Egor descubre que Cristina está muerta y la escena de amor se convierte en miedo, y Egor le lanza un candelabro encendido a Cristina en el compás 284 . Se produce un incendio, Cristina desaparece y hay un interludio orquestal, hasta el compás 298 , de dieciséis compases ${ }^{32}$ de duración que sirven para un decorado nuevo en la escena: la sala de baile del segundo acto, pero ahora en ruinas.

En ese momento aparece Radu llevando de la mano a una Sanda pálida e inconsciente (por estar muerta), y le recuerda a Egor, acompañado por el saxo barítono, de que ya le advirtió sobre Cristina (Fig. 39).

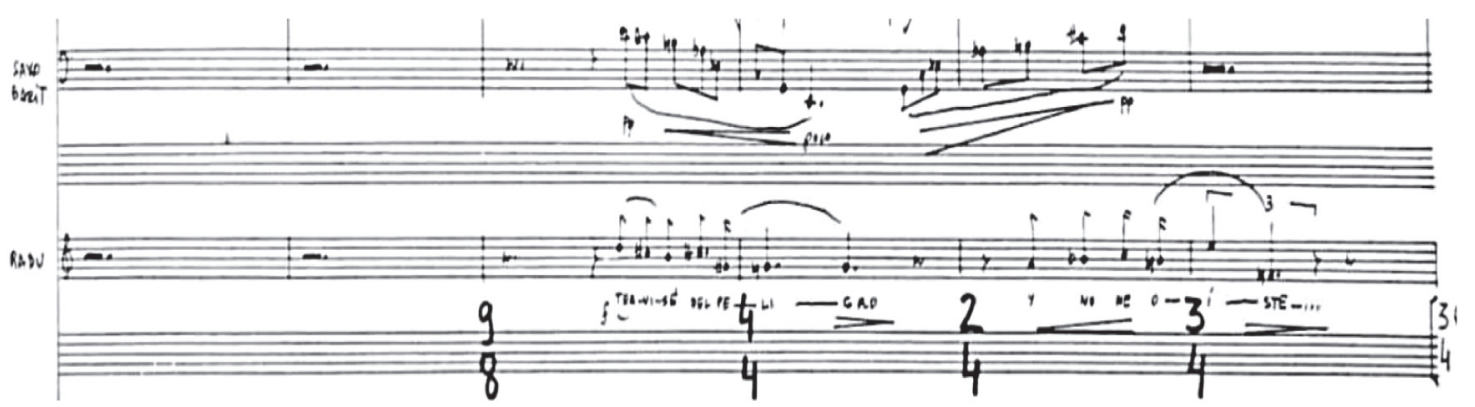

Fig. 39. Intervención de Radu junto con el saxo barítono

32 Hay seis compases repetidos en la partitura con numeración b (añadidos posteriormente, se entiende). 
Cristina aparece otra vez cantando la poesía de Eminescu que la señora Moscu recita en el segundo acto:
"Las finas cuerdas de mi pecho, por tu amor me lasti$\operatorname{man}^{33} \ldots "$

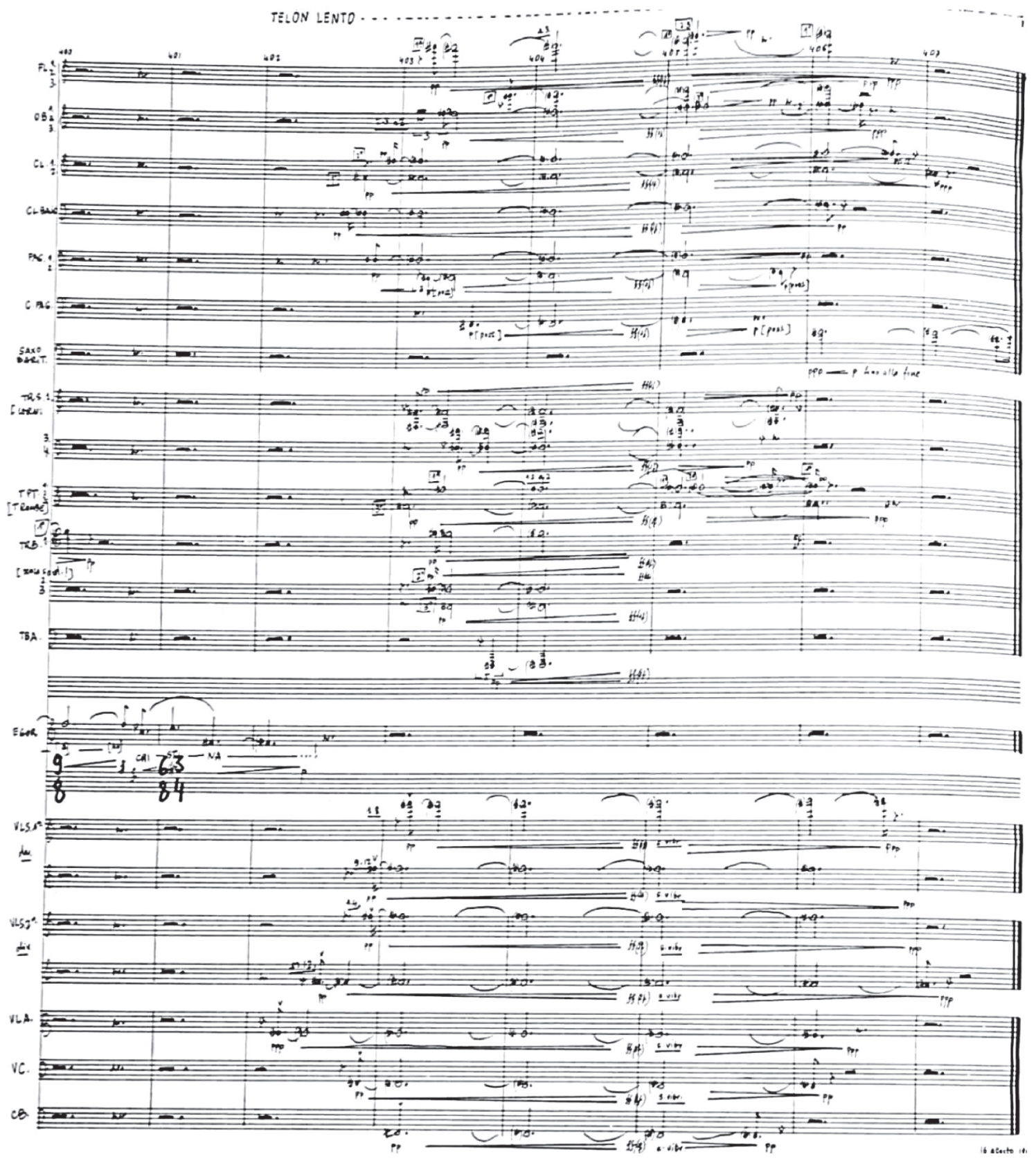

Fig. 40. Final de la obra en el que el barítono se queda sonando y es quien termina la ópera

33 PABLO COSTALES, 2001: 41 
Cristina le vaticina una muerte joven de añoranza por ella, y desaparece. Y la obra termina con una exclamación de Egor: “¡Ah, Cristina!” Y con una última nota a cargo del saxo barítono (que sugiere a Cristina), termina la ópera (Fig. 40).

Los tiempos oscilan entre $\bullet=60 \mathrm{y} \bullet=120$. El saxofón tiene una participación en la escena únicamente con el saxo barítono cumpliendo la función dramática de una Cristina ausente. Queremos decir que cuando ella está presenta el saxo no lo está, pero cuando ella está ausente y se la nombra, o se piensa en ella, entonces aparecen solos, como el que canta con Radu, o el del compás 62 (Fig. 41).

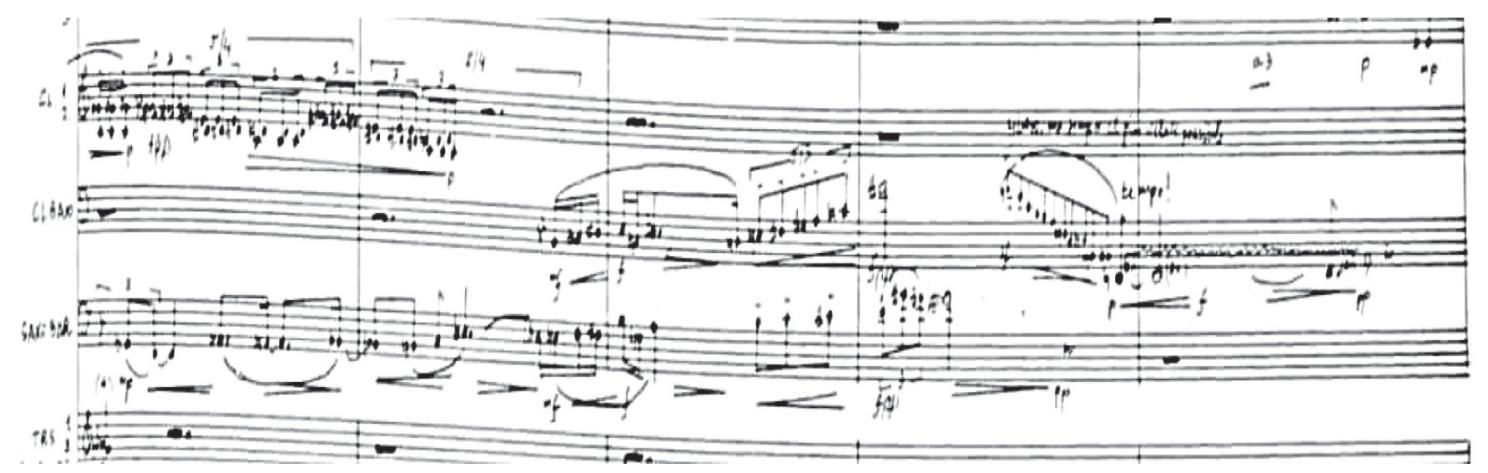

Fig. 41. Intervención del saxofón en el compás 62

En esta primera intervención la línea melódica se completa con el clarinete bajo. Otras intervenciones del saxofón son simple refuerzos de las líneas melódicas del viento madera, pero no parece que tengan una importancia dramática, salvo la presencia como timbre en la orquesta. En los momentos más dramáticos, el compositor echa mano habitualmente del repetitivo recurso de unísonos en octavas.

Las voces tienen un tratamiento diferente. Por ejemplo, Simina, en el segundo acto, presenta una interválica más abierta en determinados momentos de tensión en el argumento, mientras que el duetto entre Egor y Cristina se mueve en terceras y cuartas y muchas veces en movimiento contrario, y con una conjunción bastante consonante entre las dos voces.

Preguntado el compositor sobre qué parecido hay entre sus diferentes óperas, nos destaca la diferencia entre sus óperas de números (o sea de estilo italiano) y sus óperas sin interrupciones estilo Wagner. La señorita Cristina es de este último apartado:

[...] así como Kiu y La señorita Cristina son óperas en las que toda la música fluye de cabo a rabo sin dividirse en partes, están divididas en escenas ¿verdad? Pero que no hay números, me refiero a arias y recitativos, y en La madre y El viajero sí los hay, y es que yo me he servido de las dos técnicas. Concretamente, en
El Viajero Indiscreto, como es una obra que pasa en cualquier tiempo, como en La madre invita a comer, si tú has visto la partitura verás que la obra está dividida en una serie de números que están titulados además en italiano, en un italiano además que no es que sea churrigueresco, pero que las cosas que dice no son las ortodoxas, está escrito en un italiano que creo que es correcto, pero que no se suele emplear. Por ejemplo: antica aria espagnola con oboe obligato. Es una cosa bastante extraña que se llame así una parte de una obra, cosas de este estilo, pero eso yo me lo he inventado, eso no ha existido jamás, ¿verdad? Y está dividido en cosas de esa manera. En Kiu no es así, en Kiu va de cabo a rabo todo en un trazo, y en La señorita Cristina también es así, todo fluye ${ }^{34}$.

\section{Parámetros técnicos e interpretativos del saxofón}

Como ya hemos descrito se emplean los saxofones soprano, alto y barítono, si bien este último es el que aparece mayoritariamente a lo largo de toda la obra.

34 PABLO, Luis de: Entrevista VI, Anexo VI, en: MARTINEZ GARCIA, 2011. 


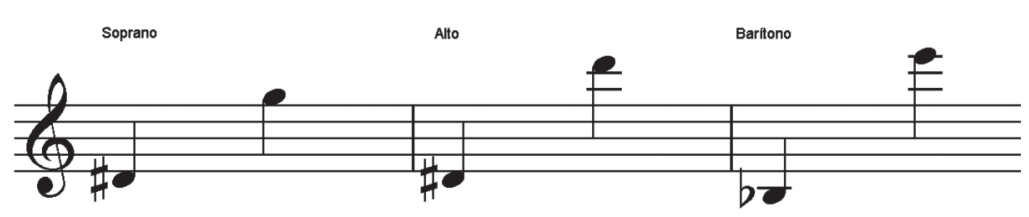

Fig. 42. Extensión de los saxos en La señorita Cristina

La tesitura empleada en cada saxo se ubica dentro de un ámbito normal, e incluso no está llevada hasta el extremo en el agudo.

La dinámica en una obra tan larga lógicamente cubre los parámetros normales desde el piano al fuerte, desde $p p$ a las $f f$ y en el caso del saxo barítono se llegan a las $f f f$.

La interválica es normal y los pasajes más abiertos son una quinta para el soprano, una octava en el alto y novena en el barítono.

Los tiempos más lentos son $\bullet=42$, y los más rápidos $\cdot=132$. En el fraseo, los pasajes de velocidad mayor son de tresillos $\bullet=100$ en el soprano, semicorcheas en $\bullet=100$ en el alto y grupos irregulares lo más rápido posible de $13=8$ en el barítono.

Las estructuras rítmicas en algunos momentos son complejas con cambios de compases y grupos irregulares. Las combinaciones rítmicas más complejas están escritas con los habituales grupos irregulares $80^{\circ}=7$ en el soprano 7.)=6$ en el alto, y $13 . \$$ en el barítono.

Los fraseos melódicos son constantes en toda la obra como hemos destacado durante el análisis.

En cuanto a efectos sonoros y técnicas contemporáneas, hay constantes cambios de timbre, y el empleo de diferentes saxofones.

El tipo de escritura está basado en el lenguaje habitual de Luis de Pablo de cambios de compás y de pulso constantemente.

\section{Aportaciones al repertorio saxofonístico}

Las óperas de Luis de Pablo son una aportación importantísima al repertorio internacional del saxofón. Si el concierto de saxofón y orquesta es una propuesta nueva en cuanto a la forma de la obra y en cuanto a la concepción del saxofón total, las óperas son una aportación capital en la historia de la música. Si en el siglo XIX las óperas de Massenet o de Bizet ofrecían un rol de personaje colorista de corta intervención en el conjunto de la obra, Luis de Pablo ofrece una participación destacadísima en todo el transcurso de la obra en todas estas tres óperas. En una como La señorita Cristina en funciones dramáticas, y en otra como en $\mathrm{El}$ viajero en interesantes dúos con las voces. Este empleo es novedoso y le otorga un papel importante para la historia del saxofón y para el futuro del repertorio de este instrumento.

La orquestación del instrumento durante el transcurso de La señorita Cristina se distribuye en los pasajes dramáticos, donde podríamos decir que interviene como personaje, ya que son solos cuya función es la de recordar la presencia de Cristina, o como elemento de presencia tímbrica en el contexto en muchos casos de pasajes a tutti, o principalmente con los instrumentos de viento. El empleo tanto de modo tímbrico como de fraseo es muy brillante y muy destacado en toda la ópera.

\section{Bibliografía}

Cristina. Milan, Suvini Zerboni, 1999.

García del Busto, José Luis, "Referencias al teatro en la música no operística de Luis de Pablo". En: "La señorita Cristina” (Programa de la ópera). Madrid, Teatro Real, 2001, 66-73.

García del Busto, José Luis, Luis de Pablo. Málaga, Orquesta Filarmónica de Málaga, 2007, 107.

Marco, Tomás, Pensamiento Musical y siglo XX. Madrid, Fundación Autor, 2002.

Martínez García, Francisco, Notas al programa. Programa de concierto. Grupo Sax-Ensemble. Madrid, Fundación Sax-Ensemble, 02.12.2006, 4-7.

Martínez García, Francisco, El saxofón en la obra de Luis de Pablo. Tesis doctoral. Madrid, Universidad Autónoma de Madrid, 2011.

Pablo Costales, Luis de, Programa de la ópera "La señorita Cristina”. Libreto. Madrid, Teatro Real, 2001, 24.

Pablo Costales, Luis de, Una historia de la música contemporánea. Madrid, Fundación BBVA, 2009.

Pablo Costales, Luis de: La ópera para De Pablo. Madrid, Fundación March.Formato electrónico en: www.march.es/musica

Téllez, José Luis, "Los vampiros son los otros". En: "La señorita Cristina” (Programa de la ópera). Madrid, Teatro Real, 2001, 52-65. 